\title{
Development of a Nanostructured Lipid Carrier (NLC) by a Low-Energy Method, Comparison of Release Kinetics and Molecular Dynamics Simulation
}

\author{
Andrea C. Ortiz ${ }^{1,2,3}$, Osvaldo Yañez ${ }^{1,3}\left(\mathbb{D}\right.$, Edison Salas-Huenuleo ${ }^{4}(\mathbb{D}$ and Javier O. Morales $1,2,3, * \mathbb{D}$ \\ 1 Department of Pharmaceutical Science and Technology, School of Chemical and Pharmaceutical Sciences, \\ Universidad de Chile, Santiago 8380494, Chile; andrea.ortiz@ug.uchile.cl (A.C.O.); \\ osvyanezosses@gmail.com (O.Y.) \\ 2 Advanced Center for Chronic Diseases (ACCDiS), Santiago 8380492, Chile \\ 3 Center of New Drugs for Hypertension (CENDHY), Santiago 8380494, Chile \\ 4 Advanced Integrated Technologies (AINTECH), Santiago 7821207, Chile; edison.salash@gmail.com \\ * Correspondence: jomorales@ciq.uchile.cl; Tel.: +56-(2)-2978-1620
}

\section{check for} updates

Citation: Ortiz, A.C.; Yañez, O.; Salas-Huenuleo, E.; Morales, J.O. Development of a Nanostructured Lipid Carrier (NLC) by a Low-Energy Method, Comparison of Release Kinetics and Molecular Dynamics Simulation. Pharmaceutics 2021, 13, 531. http://doi.org/10.3390/ pharmaceutics13040531

Academic Editor: Emanuela Fabiola Craparo

Received: 1 March 2021

Accepted: 7 April 2021

Published: 10 April 2021

Publisher's Note: MDPI stays neutral with regard to jurisdictional claims in published maps and institutional affiliations.

Copyright: (c) 2021 by the authors. Licensee MDPI, Basel, Switzerland. This article is an open access article distributed under the terms and conditions of the Creative Commons Attribution (CC BY) license (https:// creativecommons.org/licenses/by/ $4.0 /)$.

\begin{abstract}
Lipid nanocarriers have a great potential for improving the physicochemical characteristics and behavior of poorly water-soluble drugs, such as aqueous dispersibility and oral bioavailability. This investigation presents a novel nanostructured lipid carrier (NLC) based on a mixture of solid lipid glycerides, fatty acid esters of PEG 1500 (Gelucire ${ }^{\circledR} 44 / 14$ ), and an oil mix composed of capric and caprylic triglycerides (Miglyol ${ }^{\circledR}$ 812). These NLCs were developed by a simple lowenergy method based on melt emulsification to yield highly encapsulating and narrowly distributed nanoparticles $(\sim 100 \mathrm{~nm}, \mathrm{PdI}=0.1$, and zeta potential $=\sim-10 \mathrm{mV})$. Rhodamine 123 was selected as a poorly water-soluble drug model and owing to its spectroscopic properties. The novel NLCs were characterized by dynamic light scattering (DLS), zeta potential, nanoparticle tracking analysis (NTA), transmission electron microscopy (TEM), differential scanning calorimetry (DSC), and colloidal stability. The drug release was determined through a dialysis bag and vertical Franzs' cells to provide insights about the methods' suitability, revealing similar performance regardless of their different fluid dynamics. Rhodamine 123 followed a characteristic biphasic release profile owing to the swelling of the hydrophilic polymer coating and diffusion process from the lipid core as revealed by the Korsmeyers-Peppas kinetic modeling. Moreover, to elucidate the formation and incorporation of Rhodamine 123 into the NLC core, several molecular dynamics simulations were conducted. The temperature was shown to be an important condition to improve the formation of the nanoparticles. In addition, the liquid lipid incorporation to the formulation forms nanoparticles with imperfect centers, in contrast to nanoparticles without it. Moreover, Miglyol ${ }^{\circledR} 812$ improves hydrophobic molecule solubility. These results suggest the potential of novel NLC as a drug delivery system for poorly water-soluble drugs.
\end{abstract}

Keywords: lipid nanoparticle; NLC; low-energy method; Gelucire ${ }^{\circledR} 44 / 14$; drug release; Franz's cells; molecular dynamics simulations

\section{Introduction}

Nanotechnology has contributed to different technology fields, such as biomedical, food industry, chemistry, and other fields [1-3]. In pharmaceutical sciences, nanotechnology promotes drug delivery carrier development that improves the final formulations' properties. Nanocarrier development can enhance the efficacy of active molecules that present low aqueous solubility and low tissue permeability, thereby improving their bioavailability and stability [4]. Furthermore, lipid nanoparticles are an exceptional type of nanosystem due to their affinity with poorly water-soluble drugs. Nanostructured Lipid Carriers (NLC) are a new generation of nanoparticles developed to overcome some limitations of previous lipid 
nanoparticles [5]. The characteristics they give in pharmaceutical formulations to active molecules include enhanced solubility, increased storage stability, improved bioavailability and permeability, controlled release, and prolonged half-life, among others [6]. These advantages are related to the NLC components' ratio because it comprises solid lipids, liquid lipids, and surfactants suspended in aqueous media. In the literature, various materials and three types of NLC have been described [7].

Several techniques to produce NLC have been reported. They are divided into two groups classified by high and low energy processes [8]. For high-energy methods, ultrasonication or high-pressure homogenization are required. Therefore, manufacturing NLC with high energy methods, specific high-cost equipment is needed. On the other hand, low-energy approaches involve emulsification or evaporation methods. They comprise of more affordable techniques but consist of extraction steps where organic solvents are used to solubilize the lipid phase and the active component. This may leave solvent traces in the final formulation.

Once the active molecule is incorporated into the nanosystem, the NLC behavior is fundamental to understanding the release process. To evaluate the NLC release performance, diverse methodologies are described. Dialysis is the most used method, consisting of a physical separation by size using a membrane with a specific pore size. The active molecule should be able to trespass the membrane when the nanosystem releases it. Nevertheless, an immobile water layer formation in the membrane that limits the release rate is usual. Hence, testing of the slow-release formulations is suggested since the membrane transport should not be the limiting effect [9]. A method adaptation is an automatic process in Franz's cells in which a small sample amount is needed. This method is conventionally used to evaluate the in vitro release and ex vivo skin permeation of formulations. Nevertheless, Franz diffusion cells have some limitations, such as low solution hydrodynamics, poor mixing, and temperature difference between donor and receptor compartments [10]. Another critical parameter is the membrane type and MWCO because it could impact the results, since permeation kinetics may be related to the dialysis membrane porosity or the interactions between the drug molecules and membrane materials [11]. Despite the existence of previous investigations reported, a comparison between these methods at the in vitro release level from NLC has not been studied so far.

In this work, we structured a novel NLC system by a low-energy process without using organic solvents. The nanosystem was physicochemically characterized for size and particle properties (dynamic light scattering, nanoparticle tracking analysis, and transmission electron microscopy). To determine the physical state of the components in the nanoparticle a calorimetry study was carried out. Also, to understand the nanosystem behavior for a future pharmaceutical formulation, reconstitution, colloidal, and $\mathrm{pH}$ stability studies were performed. On the other hand, rhodamine 123 incorporation and release studies were evaluated using two methodologies, adjusting the kinetic models. Moreover, classical molecular dynamics simulations were carried out in order to visualize and understand how every atom in the molecular system will move over time, based on a general model of physics governing interatomic interactions [12]. A homogeneous and stable formulation was obtained. The release process was governed by Fickian diffusion, and both techniques (dialysis bag and Franz's cells) had similar release performance from NLC. Finally, the molecular dynamics simulations were used to capture a wide variety of important biomolecular processes, including the NLC self-assembly processes.

\section{Materials and Methods}

\subsection{Materials}

Gelucire $^{\circledR} 44 / 14$ was donated (Gattefosse, Lyon, France). Miglyol ${ }^{\circledR} 812$, Tween ${ }^{\circledR} 80$, Rhodamine 123 ( $\geq 85 \%$ ) were purchased (Sigma-Aldrich, St. Louis, MO, USA). Amicon Ultra ${ }^{\circledR} 10$ KDa was purchased (Merck, Darmstadt, Germany). SnakeSkin ${ }^{\mathrm{TM}}$ Dialysis Tubing of cellulose membrane with a MWCO $10 \mathrm{kDa}$ was purchased (Thermo Fisher Scientific, 
Rockford, IL, USA). A Milli Q water Ultrapure Simplicity ${ }^{\circledR}$ equipment was used to produce ultrapure water used in all experiments (Merck, Darmstadt, Germany).

\subsection{Fabrication of Nanostructured Lipid Carrier (NLC) and Loading of Rhodamine 123}

A manufacturing process was adapted from a previous report [13]. The compositions and raw material used for NLC development are shown in Table 1. This method was manufactured by melt emulsification combined with an injection technique without the requirement of high energy. Briefly, the lipid phase was composed of Gelucire ${ }^{\circledR} 44 / 14$, Miglyol ${ }^{\circledR} 812$, and Tween ${ }^{\circledR} 80$. They were added to a round bottom flask, and the aqueous phase was prepared in another glass container, both heated at $85^{\circ} \mathrm{C}$. The aqueous phase was added to the lipid phase by slow dripping under stirring for $20 \mathrm{~min}$. Finally, the formulation was cooled rapidly in a fridge at $4{ }^{\circ} \mathrm{C}$ for $30 \mathrm{~min}$ without stirring. To obtain NLC labeled (NLC-Rho), $0.5 \mathrm{mg}$ of Rhodamine 123 was incorporated into the lipid phase, and the process continues as described above.

Table 1. Raw materials to fabricate the selected nanostructured lipid carrier (NLC) formulation.

\begin{tabular}{ccc}
\hline Raw Materials & \% p/p Components & Role \\
\hline Solid lipid (Gelucire ${ }^{\circledR}$ 44/14) & 4 & Lipid component \\
${\text { Liquid lipid (Miglyol }{ }^{\circledR}}^{812}$ ) & 1 & Surfactant \\
Tween $^{\circledR} 80$ & 2 & Vehicle \\
Water & 93 & \\
\hline
\end{tabular}

\subsection{Incorporation Efficiency and Drug Loading}

To quantify Rho in NLC, the formulation was ultracentrifuged in $10 \mathrm{kDa}$ MWCO Amicon Ultra ${ }^{\circledR}$ for 20 min at 7200 rcf. Then, free Rho was separated and quantified through spectrophotometry at $512 \mathrm{~nm}$. The incorporation efficiency and drug loading percentages were determined according to the following Equations (1) and (2), respectively:

$$
\begin{aligned}
& \% \text { Incorporation efficiency }=\frac{R h o_{\text {total }}-R h o_{\text {free }}}{R h o_{\text {total }}} \times 100 \\
& \% \text { Drug Loading }=\frac{R h o_{\text {total }}-R h o_{\text {free }}}{\text { Solid lipid }+\left(R h o_{\text {total }}-R h o_{\text {free }}\right)} \times 100
\end{aligned}
$$

where $R h o_{\text {total }}$ and $R h o_{\text {free }}$ are initial Rho amounts, incorporated into the NLC-Rho preparation. The unbound Rho amount corresponds to the evaluated by spectrophotometry.

\subsection{Particle Size, Polydispersity Index, Zeta Potential Analysis, and NLC Particle Concentration}

Hydrodynamic diameter and polydispersity index (PdI) were determined by dynamic light scattering (DLS). The zeta potential was measured by Doppler laser microelectrophoresis. Each sample was measured three times, each measurement corresponds to the average of 11 determinations in aqueous medium (viscosity $=0.08872 \mathrm{cp}$, medium refractive index $=1.330$, and sample refractive index $=1.333$ ) with a wavelength of $633 \mathrm{~nm}$ with a detection angle of $173^{\circ}$ and equilibration time of $120 \mathrm{~s}$. in a Malvern Zetasizer Nano ZS equipment (Malvern Panalytical Ltd., Malvern, UK). To compare the obtained size and to determine the NCL particle concentration, Nanoparticle Tracking Analysis (NTA) was performed using a NanoSight NS300 (Malvern Panalytical, Malvern, UK) equipment. For the measurements, all samples were diluted 1:10,000 with HPLC water. The diluted samples were injected with sterile syringes into the sample chamber equipped with a $532 \mathrm{~nm}$ diode laser (green). All samples were measured in a single shutter and gain mode for $90 \mathrm{~s}$ with manual shutter, gain, brightness, and threshold adjustments at room temperature. Three measurements of each newly injected sample were performed. To determine the D10, D50, and D90 as diameters size distributions, the mean size and SD values obtained by the NTA software were based on the arithmetic values calculated with all particles analyzed. 


\subsection{Morphology of NLC}

Transmission Electron Microscopy (TEM) was performed to visualize the NLC morphology. Briefly, NLC was diluted 100 times with water, deposited on film-coated copper grids, stained with $1 \%$ phosphotungstic acid for $2 \mathrm{~min}$, washed with water, and dried for $12 \mathrm{~h}$ at room temperature. The samples were evaluated on an Inspect F50 scanning transmission electron microscope (FEI, Hillsboro, OR, USA).

\subsection{Calorimetric Evaluation of NLC}

To determine the physical state of components in NLC, Differential Scanning Calorimetry (DSC) was performed in a DSC131 (SETARAM Inc., Cranbury, NJ, USA) equipment. NLC was freeze-dried with trehalose $5 \%$ before the DSC measurement. Each sample (1-5 mg) was placed in an aluminum pan and evaluated with a temperature gradient of $25^{\circ} \mathrm{C}$ to $65^{\circ} \mathrm{C}$ at $5^{\circ} \mathrm{C} / \mathrm{min}$.

\subsection{Freeze-Drying and Reconstitution Studies}

The NLC was diluted with cryoprotectant solution (1:1) before freezing at $-80{ }^{\circ} \mathrm{C}$ overnight. Samples were lyophilized for $48 \mathrm{~h}$ at maximum vacuum. The dry products were solubilized with $1 \mathrm{~mL}$ of water and sonicated for $2 \mathrm{~min}$. The hydrodynamic diameter, PdI, and zeta potential were determined for all reconstituted samples as mentioned before (Table 2).

Table 2. Cryoprotectants used in the freeze-drying.

\begin{tabular}{cc}
\hline Cryoprotectant & Concentration (\%) \\
\hline Trehalose & $2.5,10,15$ \\
Mannitol & $2.5,10,15$ \\
Dextrose & $2.5,10,15$ \\
Lactose & $2.5,10,15$ \\
\hline
\end{tabular}

\subsection{Colloidal Stability}

The stability of the formulations (NLC and NLC-Rho) was evaluated while being protected from light for 3 months at room temperature and $4{ }^{\circ} \mathrm{C}$. Also, they were assessed at $45{ }^{\circ} \mathrm{C}$ for 1 month. The data for 12 weeks at $45{ }^{\circ} \mathrm{C}$ was not considered because it corresponds to an accelerated stability study. For each sample, hydrodynamic size, PdI, and zeta potential were recorded at different times.

\section{9. $p H$ Stability of NLC-Rho}

To study the $\mathrm{pH}$ stability of NLC-Rho, hydrodynamic diameter, PdI, and zeta potential were analyzed at room temperature in a range of $\mathrm{pH}$ conditions. Briefly, NLC-Rho was diluted in water (1:10), and the sample was titrated with $\mathrm{HCl}$ and $\mathrm{NaOH} 0.1 \mathrm{M}$ in Zetasizer Malvern Nano ZS (Malvern Panalytical Ltd., Malvern, UK) at $25^{\circ} \mathrm{C}$.

\subsection{Release Studies}

The Rhodamine 123 (Rho) release from NLC was performed through two methodologies. First, the experiment was performed using SnakeSkin ${ }^{\mathrm{TM}}$ dialysis bag (MWCO $10 \mathrm{KDa}$ ) in $10 \mathrm{~mL}$ of PBS (pH 7.4) and $400 \mu \mathrm{L}$ of sample. Second, the method was realized in vertical Franz diffusion cells (Phoenix ${ }^{\mathrm{TM}}$ DB-6) with the same SnakeSkin ${ }^{\mathrm{TM}}$ membranes, $10 \mathrm{~mL}$ of PBS (pH 7.4), and $1 \mathrm{~mL}$ of sample. Both methodologies were performed at $25^{\circ} \mathrm{C}$ and $37^{\circ} \mathrm{C}$ under continuous stirring at $400 \mathrm{rpm}$, maintaining sink conditions throughout the whole experiment. The samples were drawn at selected time intervals for $72 \mathrm{~h}$ and replaced with the same volume of fresh medium in the receptor chamber. The amount of Rho was measured in triplicate by fluorescence at $525 \mathrm{~nm}$ excitation peak. In addition, five kinetic models (zero-order, first-order, Higuchi, and Korsmeyer-Peppas functions) were used to fit the experimental data obtained from drug release studies. The coefficient of 
determination $\left(R^{2}\right)$ was used to select the model with better fitting for the experimental result and the similarity factor $\left(f_{2}\right)$, to compare the profile of both methodologies.

\subsection{Molecular Dynamics Simulations}

Molecular dynamics (MD) simulations to the four ingredients of NLC in the presence of aqueous media were performed, namely Gelucire ${ }^{\circledR} 44 / 14$, Miglyol ${ }^{\circledR} 812$, Tween ${ }^{\circledR} 80$, and Rho. The full geometry optimizations of all molecules were carried out with the density functional theory method by a hybrid functional B3LYP functional (Becke's Three Parameter Hybrid Functional Using the LYP Correlation Functional) along with the 6$31+G(d)$ basis set $[14,15]$. All molecules were parameterized using the LigParGen web server and implementing the OPLS-AA $/ 1.14^{*} \mathrm{CM} 1 \mathrm{~A}(-\mathrm{LBCC})$ force field parameters for organic ligands [16-18]. The simulations were carried out using an explicit solvent with the TIP3P-FB water model ( $\approx 50.000$ water molecules), within the OpenMM software [19-21]. Starting configurations were generated in cubic boxes with lateral dimensions of $120 \AA$ set up with three-dimensional periodic boundary conditions. The system was initially prepared by placing all the molecules at random in the simulation box using a packing molecule in defined regions of space called Packmol [22]. First, each system was minimized (40,000 steps) and equilibrated ( $5 \mathrm{~ns})$. Then, 200-ns-long production MD simulations were performed on each system. During the MD simulations, the equations of motion were integrated with a 2-fs time step in the NPT ensemble at a pressure of $1 \mathrm{~atm}$. The SHAKE algorithm was applied for all hydrogen atoms, and the Van der Waals cutoff was set to $12 \AA$. The temperature was maintained at $300 \mathrm{~K}$ for one system, and for the other three systems, it was $358 \mathrm{~K}$ (experimental temperature during NLC synthesis) by employing the Langevin thermostat method with a relaxation time of 1 ps. The Monte Carlo barostat was used to control the pressure of $1 \mathrm{~atm}$. Long-range electrostatic interactions were considered by means of the Particle Mesh Ewald (PME) approach. Data were collected every 1 ps during the MD runs. Molecular visualization of the systems and MD trajectory analysis were carried out with the VMD software package [23].

\subsection{Non-Covalent Interaction Index}

To reveal the possible non-covalent Rho molecules in the presence of the mixed NLC interactions, such as hydrogen bonds, steric repulsion, and Van der Waals interactions, the non-covalent interaction index (NCI) was used [24,25]. The NCI is based on the electron density $(\rho)$, its derivatives, and the reduced density gradient (s). In this work, the promolecular densities ( $\rho$ pro), computed as the sum of all atomic contributions were used. The NCI was calculated using the NCIPLOT program [24].

\subsection{Data Analysis and Statistics}

All experiments were performed in triplicate, and all the data were expressed as the mean value \pm standard deviation (SD). The statistical data analysis was conducted by Student's t-test, with a $p$-value $<0.05$, using the GraphPad Prism software version 6.01. To evaluate the kinetic fit and the similarity factor $\left(f_{2}\right)$, the DDSolver add-In (Microsoft Excel) program was used.

\section{Results and Discussion}

\subsection{Low-Energy Synthesis and Physicochemical Properties of Novel NLC}

Different methods have been reported to produce NLC. The most recent studies use high-energy techniques, such as ultrasonication or high-pressure homogenization [26]. The low-energy methods are based on the spontaneous formation of droplets when the ratio composition (surfactant/oil/water) is modified [27]. These methods include microemulsification, double emulsification, phase inversion temperature, coacervation, and membrane contactor [28]. Generally, the NLC synthesis by low-energy methods is usually combined with an organic solvent or stirring process [29]. The method used in this work is based on a previous report that utilizes the same solid lipid. The lipid nanoparticles obtained 
had a comparable size and dispersity to those obtained here; however, our manufacturing process does not use high energy such as ultrasonic cell disrupt to obtain a comparable nanoparticle size [13]. Carbone et al. synthesized a NLC loaded with ferulic acid through phase inversion temperature. Their results showed a hydrodynamic diameter and PdI values of $<50 \mathrm{~nm}$ and $\sim 0.3$, respectively [30]. Along the same lines, Sun et al. developed a similar method to manufacture NLC, with hydrodynamic size results of $<100 \mathrm{~nm}$ and PdI $>0.3$ [31]. In comparison, our NLC obtention strategy needs low energy but does not use organic solvents and it is a quick process compared with other reported methodologies. The obtained nanoparticles have $\sim 100 \mathrm{~nm}$ with PdI lower than 0.15 (Figure 1).

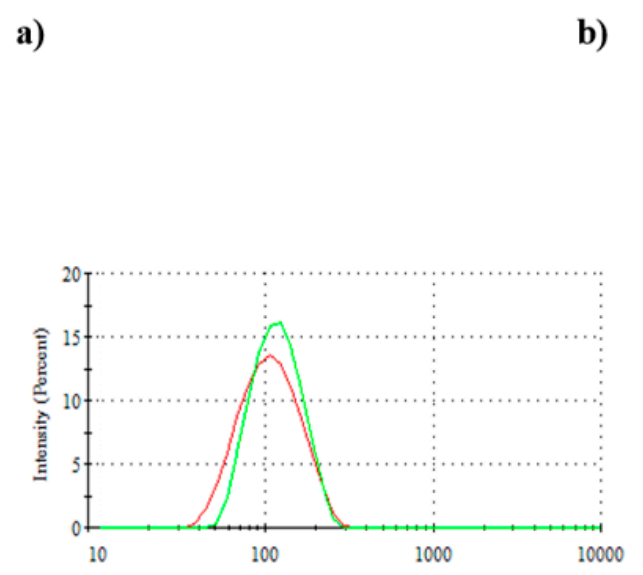

d)

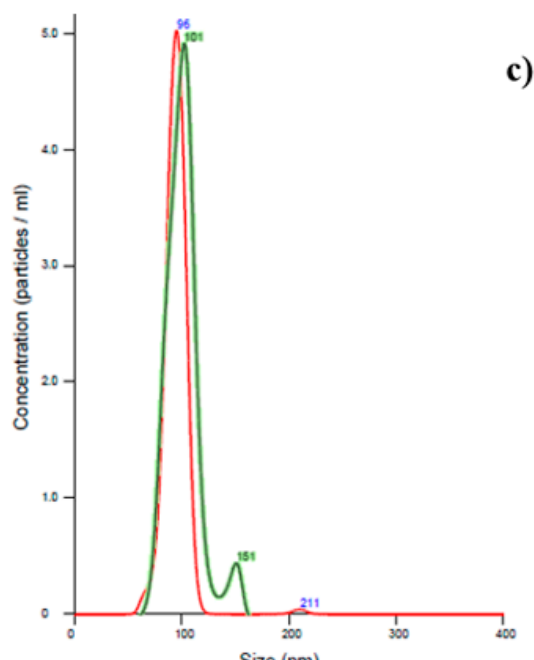

c)

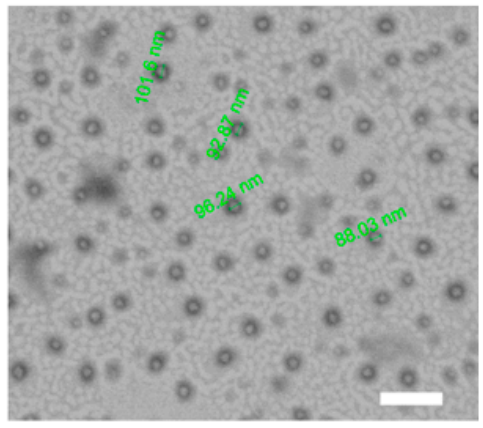

\begin{tabular}{|c|c|c|c|c|c|}
\hline \multirow{2}{*}{ Nanomaterials } & \multicolumn{2}{|c|}{$\begin{array}{c}\text { Hydroynamic Diameter } \pm \\
\text { SD }(\mathrm{nm})\end{array}$} & \multirow{2}{*}{$\mathrm{PdI} \pm \mathrm{SD}$} & \multirow{2}{*}{$\begin{array}{c}\text { Zeta Potential } \pm \text { SD } \\
(\mathrm{mV})\end{array}$} & \multirow{2}{*}{$\begin{array}{l}\text { Particle concentration } \\
\pm S D \text { (particle } / \mathrm{mL} \text { ) }\end{array}$} \\
\hline & DLS & NTA & & & \\
\hline NLC & $90.3 \pm 5.6$ & $98.6 \pm 16.5$ & $0.147 \pm 0.04$ & $-9.5 \pm 0.6$ & $1.0 \times 10^{13} \pm 6.8 \times 10^{7}$ \\
\hline NLC-Rho & $106.7 \pm 1.6$ & $116.2 \pm 12.3$ & $0.132 \pm 0.01$ & $-9.3 \pm 0.6$ & $4.7 \times 10^{13} \pm 2.5 \times 10^{9}$ \\
\hline
\end{tabular}

Figure 1. Characterization of NLC (red line) and NLC-Rho (green line). (a) Hydrodynamic diameter distribution, (b) Nanoparticle Tracking Analysis, (c) TEM image of NLC (the bar represents $500 \mathrm{~nm}$ ), and (d) Hydrodynamic diameter $(\mathrm{nm})$, PdI, and zeta potential $(\mathrm{mV})$ by DLS.

In pharmaceutical applications, the nanoparticle size and dispersion are crucial parameters to assure an optimal formulation behavior in terms of stability, arrival at the site of action, delivery, and safety. In the high-energy method, sonication and high-pressure homogenization are key steps to decrease nanoparticle size [32]. In the low-energy methods, the temperature is a determining factor in reducing the size and dispersion. In this context, the fundamental steps in the low-energy process are (i) high and constant temperature that permits the solid lipids, surfactant, oil, and cargo an adequate mixing [33]; (ii) slow dripping, continuous agitation, and high temperature that allows the $\mathrm{O} / \mathrm{W}$ drop to structure with an optimal size dispersion in the nanometric range [34]; (iii) high-temperature gradients to facilitate the rapid lipid crystallization, preventing aggregation. Moreover, at high temperatures, the hydrophilic head of the non-ionic surfactant begins to be more dehydrated than the hydrophobic tail, which is why $\mathrm{W} / \mathrm{O}$ formulations are favored. However, when the temperature is lowered, the surfactant head is more hydrophilic than the tail and forms $\mathrm{O} / \mathrm{W}$ formulations [35]. Therefore, the cooling process is an essential step because it allows solid lipid solidification and helps maintain the size and monodispersion [36].

Regarding the process described above, Gelucire ${ }^{\circledR} 44 / 14$ has a fundamental role in the formulation due to the amphiphilic self-assembly characteristics, forming a fine dispersion in contact with aqueous media [37]. The Gelucire ${ }^{\circledR} 44 / 14$ melting point is $44{ }^{\circ} \mathrm{C}$; 
therefore, nanoparticles can be solidified without requiring a large temperature difference. Furthermore, it can be used as a binder in melt methods, and due to its thermoplastic behavior, it allows the rapid formation of stable crystalline structures [38]. Mygliol ${ }^{\circledR} 812$, a liquid lipid component at room temperature, contributes to the mixing process, allowing the components dissolution and the incorporation of higher Rho quantities in the NLC core [39]. Finally, Tween ${ }^{\circledR} 80$, contributes to the NLC formation and stabilization in aqueous media and, with Gelucire ${ }^{\circledR} 44 / 14$, maintains the NLC stability over time [40]. These results are consistent with the observed in the molecular dynamics simulations (Section 3.9).

In general, physical parameters such as a spherical shape, low size distribution, and a zeta potential range of up to $\pm 35 \mathrm{mV}$ are acceptable characteristics to obtain improved stability and low toxicity [41]. In this study, we used different materials and components ratios (Table S1). Accordingly, we selected a formulation based on these parameters (Figure S1). The NLC and NLC-Rho nanosystems had a hydrodynamic diameter measured by DLS, around 90 and $100 \mathrm{~nm}$, respectively. The sizes were consistent with the NTA determination, and the obtained zeta potential was $<-9.5$ for both systems (Figure 1). As Pimentel-Moral et al. considered, the NCL and NCL-Rho nanosystems were characterized as monodisperse with a PdI of $<0.15$ [42].

A manufacturing advantage of using high-energy methods is the low size dispersion obtained. The sonication and high-energy mixing allow the obtention of PdI around $0.1-0.3$ [43]. In our formulation, the low size distribution is attributed to the cooling process. The solid lipids solidify at temperatures below $44{ }^{\circ} \mathrm{C}$, and the lipid droplets formed in the process partially solidify and prevent the coalescence [44]. The negative zeta potential was attributed, in part, to the surfactant and some free fatty acids in the interface, such as derived from the glyceride hydrolysis present in Gelucire ${ }^{\circledR} 44 / 14$ [45]. The obtained zeta potential indicates a low nanoparticle electrostatic repulsion, thus slightly preventing the aggregation. Nonetheless, the free esters of PEG, free PEG in Gelucire ${ }^{\circledR} 44 / 14$ and Tween ${ }^{\circledR} 80$ contribute to forming hydrophilic nanoparticles and improve the stability of NLC by steric interaction, hydration in the surface layer, and resistance to flocculation and coalescence [46]. Despite this, the surface charge is a crucial factor for biocompatibility and can determine nanoparticle behavior in a biological context. Processes such as cellmembrane interactions, internalization, opsonization, and biological fluid stability can be governed by the charge of the nanosystem [47]. Thus, positively charged nanoparticles can internalize it more actively than neutral or negative nanoparticles [48]. However, nanoparticles with a slightly negative surface tend to accumulate in tumor tissues more efficiently [49]. On the other hand, positive nanoparticles can activate faster immune responses than neutral or negative nanoparticles [50].

Both NLC and NLC-Rho were kept in the nanometric range because the formulations have a D90 less than $140 \mathrm{~nm}$. Besides, appropriately dispersed and spatially separated nanoparticles were visualized in the video obtained from the Brownian motion of NLC in suspension. The particle concentration was determined by NTA. Both formulations presented near 1013 particle/mL (Figure 1b). NTA determination has some advantages compared with the DLS, mainly the precise sizing, reliable size distribution, and easy detection of contaminants [51]. Also, with NTA it is possible to visualize the nanoparticle trajectory following the Brownian movement in a real-time period. This is possible while the particle is visible or intersects with an adjacent particle [52]. For these reasons, it is always proper to evaluate a nanosuspension by NTA and compare it with the DLS method. NTA is a useful tool in the pharmaceutic field related to nanotechnology because it allows knowing the particle concentration, which gives us valuable information to understand the doses of the active molecules carried by the nanosystems.

\subsection{Morphology}

To determine NLC shape and morphology they were visualized by TEM. It was observed that NLC has a spherical shape and monodisperse size distribution among the evaluated samples, indicating the reproducibility of the process (Figure 1c). The spherical 
shape results due to the homogenization process, because of the reduced surface tension provoked by the presence of Tween ${ }^{\circledR} 80$, and spherical nanoparticles formed are stabilized after the cooling process. The minimum interfacial energy facilitates the formation of a closer spherical bilayer. However, nanoparticle self-assembly is not spontaneous. The steric or ionic repulsion between hydrophobic and hydrophilic materials are the promoters, requiring the application of external energy [53]. A slight difference can be noted between the obtained sizes by TEM and DLS. This difference is because the TEM images reveal the size of the solid-state after a drying process. Thus, contributing to nanoparticles acquiring a flattened shape and increased size [45]. In contrast, DLS measures the nanoparticle in aqueous solutions, tending to exhibit a larger size due to the solvation layer [54].

\subsection{Physical State Evaluation of NLC}

Differential Scanning Calorimetry is a powerful approach to study the components' physical state in a nanoparticle formulation. The pure materials, physical mixture, and NLC thermogram profiles are shown in Figure 2. Gelucire ${ }^{\circledR} 44 / 14$ has the melting point at $44^{\circ} \mathrm{C}$. In the case of Gelucire ${ }^{\circledR} 44 / 14$ mixture, a displacement of the melting point from $44{ }^{\circ} \mathrm{C}$ to $40{ }^{\circ} \mathrm{C}$, and $38^{\circ} \mathrm{C}$ in the lyophilized NLC was observed. This suggests that the mixture between Miglyol ${ }^{\circledR} 812$ and Tween ${ }^{\circledR} 80$ could partially solubilize the solid lipids and favor an earlier fusion. Moreover, lyophilized NLC and physical mixture revealed a different behavior, observing an earlier fusion in the lyophilized system. This difference suggests a closer component interaction due to the nanoparticle structuration. During the manufacturing process, the solid lipids, liquid lipids, and surfactant are in close contact at high temperatures. Then, when the temperature drops abruptly, the components are homogenized and kept in close contact.

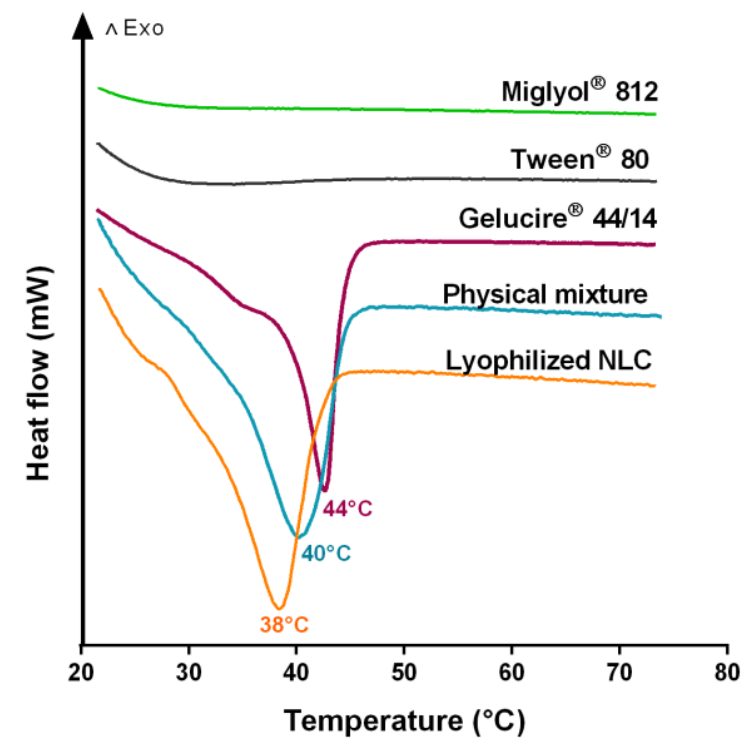

Figure 2. Differential scanning calorimetry (DSC) thermograms of Miglyol ${ }^{\circledR}$ 812, Tween ${ }^{\circledR}$ 80, Gelucire $^{\circledR} 44 / 14$, physical mixture of NLC and lyophilized NLC. The figure was produced with a representative profile of repetitions $(n=1)$.

For this reason, as the temperature increases, the near contact between components decreases the melting point. Regarding the solubility of Gelucire ${ }^{\circledR} 44 / 14$ in the presence of Tween $^{\circledR} 80$ and Miglyol ${ }^{\circledR} 812$, some reports have evaluated it by X-ray crystallography. In this context, Damian and coworkers have reported that Gelucire ${ }^{\circledR} 44 / 14$ has a transition phase at $19.23^{\circ} \mathrm{C}$ and $23.38^{\circ} \mathrm{C}$ [55]. In another research, Caon et al. reported that Gelucire ${ }^{\circledR}$ $44 / 14$ has a crystalline structure in mixture with Tween ${ }^{\circledR} 80$. Consequently, the surfactant does not solubilize the solid lipids in these conditions [56]. However, Čerpnjak et al., in 2014, studied a similar formulation, composed of Gelucire ${ }^{\circledR} 44 / 14$, Mygliol $^{\circledR} 812$, Peceol ${ }^{\mathrm{TM}}$, and Solutol ${ }^{\circledR} \mathrm{HS}$ 15. Peceol ${ }^{\mathrm{TM}}$ is an oil, composed of glycerides with long-chains, similar 
to one of the components of Gelucire ${ }^{\circledR} 44 / 14$, and Solutol ${ }^{\circledR}$ HS 15 has a similar HLB than Tween ${ }^{\circledR} 80,16$ and 15, respectively. According to these approaches, the crystalline structure of Gelucire ${ }^{\circledR} 44 / 14$ was not visible in the formulation with Miglyol ${ }^{\circledR} 812$ and surfactants. Thus, this liquid lipid may improve the solubility of Gelucire ${ }^{\circledR} 44 / 14$ [57].

\subsection{Freeze-Drying and Reconstitution Studies}

Solid dosage forms are preferred due to their greater stability over time. As such, it is relevant to evaluate the drying and reconstitution process of the formulations. Lyophilization is one of the most common techniques to remove the aqueous medium from a suspension. It consists of sublimation in which the sample undergoes stress in the freezing and drying process. Therefore, cryoprotectants are used to preserve the nanoparticles avoiding possible agglomerations [58]. Carbohydrates have been widely used as cryoprotectants due to their ability to inhibit water crystallization. We used four types of this category, evaluating different concentrations (Table 2) [59]. In general, with a higher concentration of cryoprotectants, the system will reconstitute better [60], which was consistent with our results. Specifically, the highest concentrations of trehalose, mannitol, and lactose show similar behavior, and nanoparticles with similar characteristics to the control were obtained (Figure 3). On the contrary, all the formulations prepared with dextrose resulted in nanoparticles with high hydrodynamic diameters close to $400 \mathrm{~nm}$, revealing aggregation. However, they have a zeta potential of $-30 \mathrm{mV}$, which indicates an electrostatically stable system. The carbohydrate cryoprotectant role lies in the hydroxyl group's availability. The generation of hydrogen bonding sites per molecule directly relates to depressing the freezing points at the nanosystem's edges. Because of this, trehalose, lactose, and mannitol, with 8,8 and 6 available hydroxyl groups, respectively, had better performance than dextrose with only 5 .

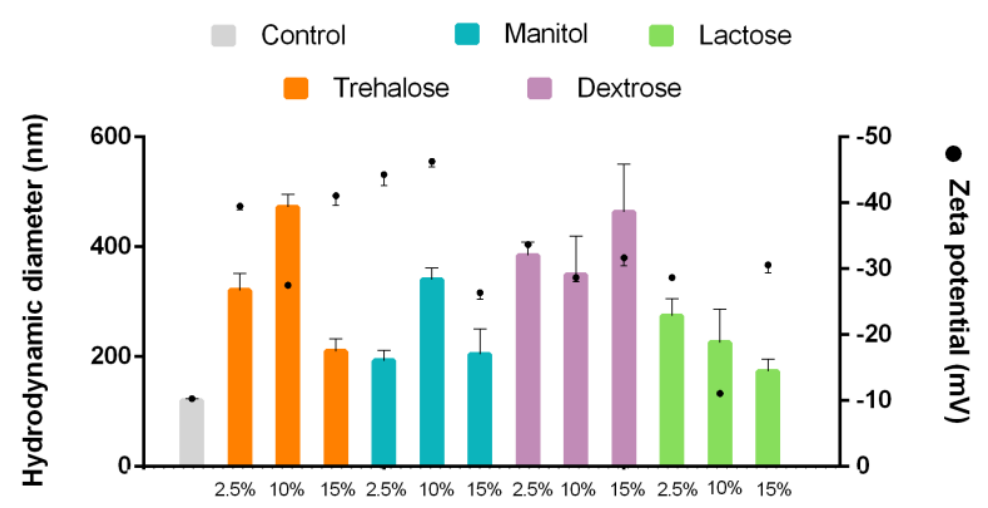

Figure 3. Hydrodynamic diameter and zeta potential of control and reconstitution of NLC with different concentrations of cryoprotectants. $n=3 \pm$ SD.

\subsection{Incorporation Efficiency and Drug Loading}

Nanoformulations play essential roles in carrying drugs with low permeability and/or solubility (BCS type II and IV) and the subsequent controlled release. In this research, Rhodamine 123 (Rho) was selected as a drug model due to its high lipophilicity, low solubility in aqueous media (BCS type II), and the opportunity to follow it by fluorescence. Usually, Rho is incorporated in nano/microparticles to label and monitor in vivo studies [61]. Rho has a high extinction coefficient, thus does not require elevated concentration to follow it and determine the delivery ratios. After NLC-Rho ultracentrifugation, unbound Rho was quantified by Uv-vis, and $418 \mu \mathrm{g} / \mathrm{g}$ solid lipid was determined. After the free-Rho separation, the incorporation efficiency and drug loadings were $93.5 \%$ and $0.03 \%$, respectively. Rho was highly incorporated due to its affinity to lipids than the aqueous phase. Besides, NLC forms an imperfect core and an amorphous matrix; this also allows for a greater incorporation of lipophilic molecules because it can accommodate molecules and prevent their abrupt drug escape in storage conditions [62]. 


\subsection{Colloidal Stability}

The studies on lipid nanoparticle stability indicate a general tendency toward instability over short times. In general, authors refer to instability due to the crystal growth by Ostwald ripening and mushroom-like arrangement of the short chains of PEG [63]. In our case, we used a solid lipid with a long chain of triglycerides, and the cold process in the fabrication prevents the Oswalt ripening. On the other hand, the nanosystem's physical stability is a critical characteristic. Based on visual examination, all formulations were still homogeneous in the long term, and no visible free lipids or system rupture was evidenced. We determined that NLC at room temperature and $4{ }^{\circ} \mathrm{C}$ for 4 weeks did not change the size (Figure 4). When NLC was incubated at $45^{\circ} \mathrm{C}$ a size increase of $\sim 40 \mathrm{~nm}$ was evidenced, attributed to agglomeration. As shown in Figure 2, the thermogram of lyophilized NLC has a fusion peak at $38^{\circ} \mathrm{C}$; therefore, nanoparticles begin a state of change due to the fusion process. However, PdI remained constant in a narrow range of 0.1-0.2. The size increase possibly corresponds to a slight agglomeration or due to a homogenous agglomeration growth [64]. The size increasing over time can be mediated by gravitational separation, flocculation, or Ostwald ripening mechanisms. To avoid Oswald ripening, it is necessary to incorporate a non-polar agent, with oil phase solubility but insoluble in the aqueous phase. Some of these agents can be triacylglycerols, diacylglycerols, monoacylglycerols, and free fatty acids. Gelucire ${ }^{\circledR} 44 / 14$ is composed of a long chain of triacylglycerides, mono- and di-fatty acid esters of PEG 1500, that inhibit the Oswald ripening process and decrease the size distribution [65]. Both formulations kept an average of $-8 \mathrm{mV}$ in charge by zeta potential, suggesting possible colloidal instability due to the closeness to neutrality. Nevertheless, it was evidenced that the nanosystem remains stable over time, explained due to the steric distancing between the nanoparticles produced by the formulation's components. In general, polymeric material induces steric stabilization. In the case of lipid nanoparticles, this role is usually accomplished by surfactant. However, the main component in this formulation is Gelucire 44/14, composed of polyethyleneglycol that improves the stability along with Tween ${ }^{\circledR} 80$. Thermodynamically steric stabilization is determined by estimating Gibb's free energy, and the strong enthalpic interaction is due to the efficient solvation between the solvent and the stabilizing agent (surfactant). In addition, a nonionic surfactant can give a solvation barrier to a close contact. Then, stabilization segments cannot interpenetrate with another nanoparticle producing a steric stabilization. The solvation barrier is considered an additional force in the DLVO model. Modern DLVO variants include calculations of Van der Waals forces, electrostatic forces, and solvation forces. Accordingly, the nanosystem is stabilized by the electrostatic effect and steric hindrance NLC and NLC-Rho are presented an interesting colloidal stability.
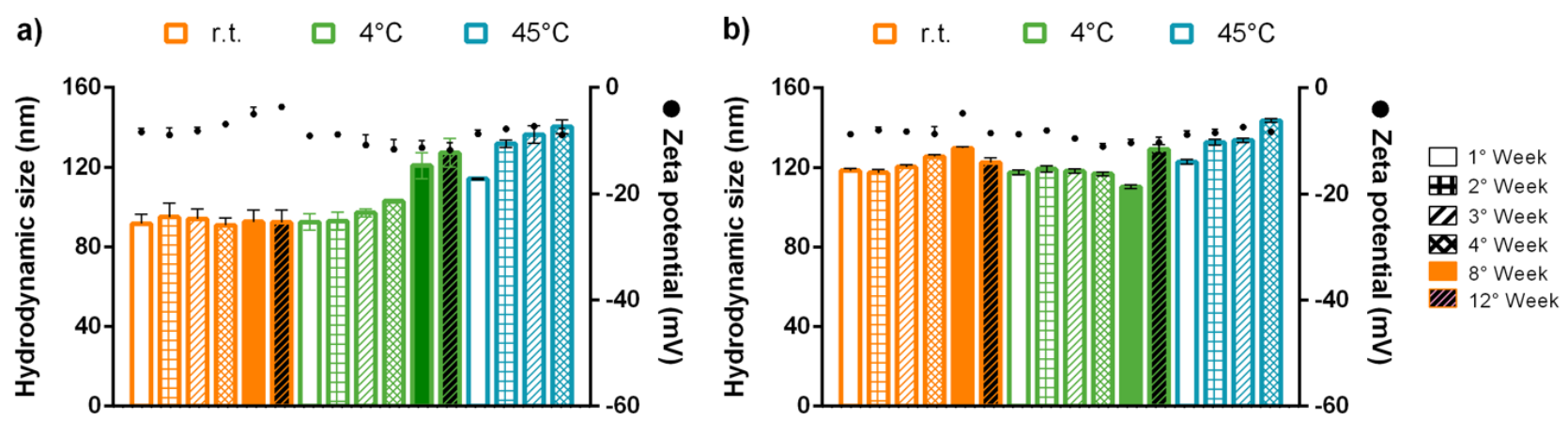

Figure 4. Colloidal stability studies of (a) NLC and (b) NLC-Rho at room temperature and $4{ }^{\circ} \mathrm{C}$ for 12 weeks and $45^{\circ} \mathrm{C}$ for 4 weeks. Parameters evaluated were hydrodynamic size $(\mathrm{nm})$, and zeta potential $(\mathrm{mV}) . n=3 \pm \mathrm{SD}$.

\section{7. $p H$ Stability of NLC-Rho}

Given the potential administration via the oral route, the NLC behavior at different $\mathrm{pH}$ present in the gastrointestinal tract gives us an insight into the real condition of the 
system applicability. The gastrointestinal tract has a $\mathrm{pH}$ range from acidic as 2 and slightly basic as 8 , which can affect the nanosystem structure. In the evaluated $\mathrm{pH}$ range, the hydrodynamic diameter did not change drastically, but PdI increased until 0.2; this was attributed to a change in the superficial charge at lower $\mathrm{pH}$ (Figure $5 \mathrm{a}, \mathrm{b}$ ). Tween ${ }^{\circledR} 80$ is a nonionic surfactant and acts as a stabilizer, however, it has a negative charge in the interface, because of the differential adsorption of the hydroxyl ion $\left(\mathrm{OH}^{-}\right)$and hydrated oxonium ion $\left(\mathrm{H}_{3} \mathrm{O}^{+}\right)$. The polyoxyethylene group was neutralized, then the zeta potential increased, which could allow the nanoparticle aggregation, increasing the PdI [66]. In 2017, Park et al. investigated about vitamin D3 incorporation in NLC. They observed that the NLC zeta potential at $\mathrm{pH} 2$ and $\mathrm{pH} 10$, changed from $\sim 0 \mathrm{mV}$ to $-30 \mathrm{mV}$, respectively. The authors suggest that this is due to anionic species' presence on the surface [67]. Ozturk et al. evaluated the influence of different carrier lipid types on the bioaccessibility of the D3 vitamin. In the research, they described that the generation and release of anionic free fatty acids from the matrix increase in an alkaline environment and contribute to a negative surface [68]. Therefore, the nanosystem surface charge variations can be used to direct the system along the gastrointestinal tract. At an acidic $\mathrm{pH}$, NLC has a slightly neutral charge, which allows it to have closer contact with the gastric mucosa (negatively charged). On the other hand, at a basic $\mathrm{pH}$ similar to the final third of the gastrointestinal tract, NLC can be administered locally and ensure improved electrostatic stability of the nanosystem.

a)

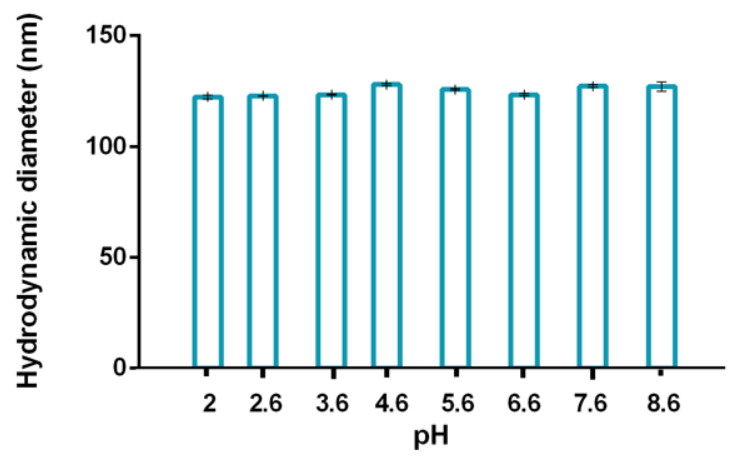

b)

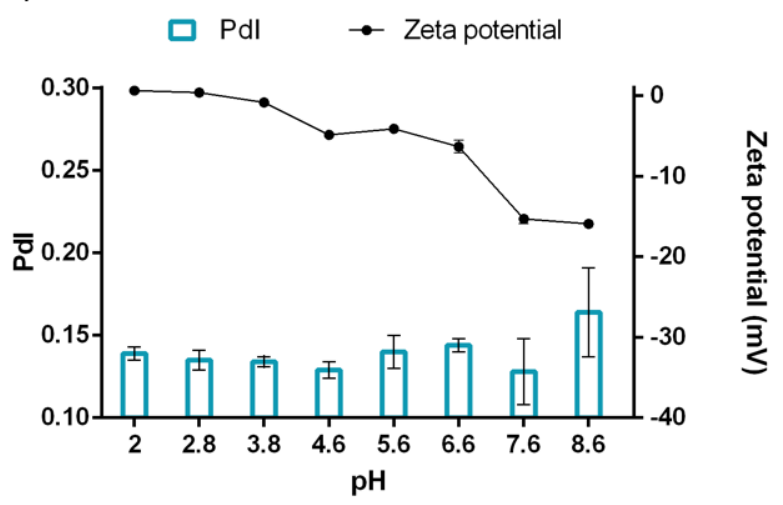

Figure 5. $\mathrm{pH}$ stability of NLC-Rho, parameters evaluated by (a) Hydrodynamic diameter and (b) PdI and zeta potential $(\mathrm{mV}) . n=3 \pm \mathrm{SD}$.

\subsection{Release Studies}

To evaluate the NLC-Rho release behavior, dialysis bag and vertical Franz's cells methods were performed. Dialysis bag is a gold standard method to determine the molecule release from different kinds of nanoparticles. Franz's cells are usually used to evaluated skin permeation, nevertheless, is an instrument that allows release studies from a matrix [9]. It is an automatic method; hence, temperature, stirring, sampling time control, and reproducibility are more precise than dialysis bags. Consequently, the variability of the results is less in Franz's cells than dialysis bag method. Also, the dialysis membrane was selected with an adequate pore size to allow a free drug diffusion and not the nanosystem, while avoiding membrane-drug interaction. Therefore, the release profile is mainly attributed to the rhodamine 123 diffusion from the lipid matrix instead of a rhodamine 123-membrane interaction that could contribute to the observed profile. The membrane superficial area in dialysis bag and Franz's cells was $1.38 \mathrm{~cm}^{2}$ and $0.63 \mathrm{~cm}^{2}$, respectively. Both experiments were performed at $\mathrm{pH} 7.4$ for $72 \mathrm{~h}$ and the results show that the Rho release at $25{ }^{\circ} \mathrm{C}$ through dialysis bag and Franz's cells were $33.7 \%$ and $42.5 \%$, respectively (Figure 6a). In the case of $37^{\circ} \mathrm{C}$ by dialysis bag and Franz's cells were $49.9 \%$ and $40.3 \%$, respectively (Figure $6 \mathrm{~b}$ ). 
a)

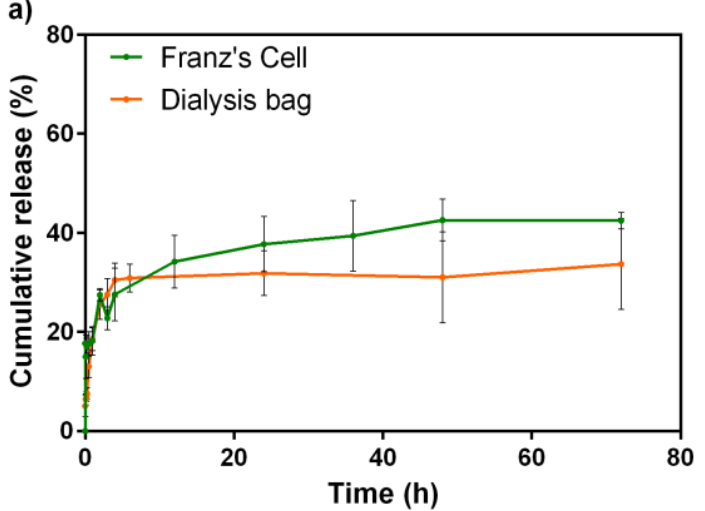

b)

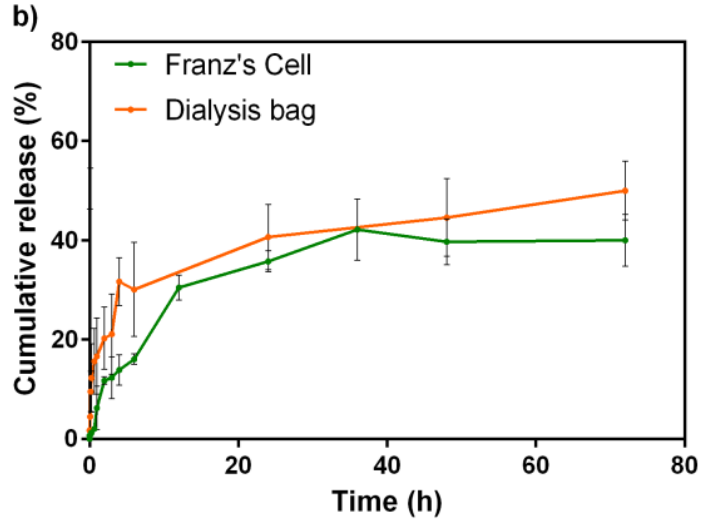

Figure 6. Cumulative release of Rhodamine $123(\%)$ at (a) $25^{\circ} \mathrm{C}$ and (b) $37.5{ }^{\circ} \mathrm{C}$ during $72 \mathrm{~h} . n=3 \pm \mathrm{SD}$.

Drug release from nanoparticles has different mechanisms depending on their composition, including matrix erosion, diffusion, or swallowing. In lipid nanoparticles, the drug release process is mainly governed by matrix diffusion and erosion [69]. Specifically, in NLC, the incorporation of a liquid lipid component in the formulation results in a less-ordered structure that prevents drug expulsion [70]. Regarding kinetic fit studies, were performed to zero order, first order, Higuchi and Korsmeyer-Peppas, resulting from this last how the better fit. In the case of the release at $25^{\circ} \mathrm{C}$, the process could be dominated by Fickian diffusion (Case I) $(n<0.43)$ (Table 3) [71], this indicates that the diffusion process is faster than the matrix relaxation. About the release at $37^{\circ} \mathrm{C}$, the process is dominated by anomalous diffusion $(0.43<n<0.85)$, therefore, diffusion is not the only process involved because the matrix is partially altered [72]. These results are concordant because, at $25^{\circ} \mathrm{C}$, the matrix is in the original state, Gelucire ${ }^{\circledR} 44 / 14$ continuous in solid-state and permit the Rho diffusion. Instead, at $37^{\circ} \mathrm{C}$, the matrix experiments physical changes due to the higher temperature, therefore Rho diffuses, but the structure becomes more labile. Furthermore, similar to our evaluation, other researchers have conducted kinetic studies of NLC. Alam et al. described a NLC that released $84 \%$ simvastatin in $24 \mathrm{~h}$, and the best fit model was Korsmeyer-Peppas $\left(\mathrm{R}^{2}=0.985\right.$ and $\left.n=0.49\right)$ [73]. In a recent study, Eh Suk et al. evaluated several NLC formulations, concluding that even though Korsmeyer-Peppars is a model for polymeric matrices, it well represents release from NLC [74].

Table 3. Kinetic fit evaluation to NLC-Rho at $25^{\circ} \mathrm{C}$ and $37^{\circ} \mathrm{C}$ in dialysis bag and vertical Franz's cell. In equations $Q_{0}$ and $Q_{t}$ is the initial amount of Rho and the amount of Rho dissolved at time $t$, respectively. $Q_{t} / Q_{\infty}$ is the fractional release of $R h o, K_{0}$ is the zero order constant, $K_{1}$ is the first order constant, $K_{H}$ is the Higuchi constant, $\mathrm{k}_{\mathrm{KP}}$ is the Korsmeyer-Peppas constant and $\mathrm{n}$ is the diffusional exponent.

\begin{tabular}{lccccc}
\hline \multirow{2}{*}{ Kinetic Models } & & \multicolumn{2}{c}{ Dialysis Bag } & \multicolumn{2}{c}{ Franz's Cell } \\
& & $\mathbf{2 5}{ }^{\circ} \mathbf{C}$ & $\mathbf{3 7}{ }^{\circ} \mathbf{C}$ & $\mathbf{2 5}{ }^{\circ} \mathbf{C}$ & $\mathbf{3 7}{ }^{\circ} \mathbf{C}$ \\
\hline Zero order & $\mathrm{K}$ & 1.92 & 2.20 & 2.48 & 1.83 \\
$Q_{t}=Q_{0}+K_{0} t$ & $\mathrm{R}^{2}$ & -1.16 & 0.78 & -1.93 & 0.77 \\
\hline First order & $\mathrm{K}$ & 0.03 & 0.03 & 0.03 & 0.02 \\
$\ln Q_{t}=\ln Q_{0}+K_{1} t$ & $\mathrm{R}^{2}$ & -0.45 & -0.05 & -1.50 & 0.86 \\
\hline Higuchi & $\mathrm{K}$ & 10.08 & 10.75 & 10.43 & 7.43 \\
$Q_{t}=K_{H} \sqrt{ } t$ & $\mathrm{R}^{2}$ & 0.46 & 0.73 & -0.19 & 0.96 \\
\hline \multirow{2}{*}{ Korsmeyer-Peppas } & $\mathrm{n}$ & 0.25 & 0.59 & 0.15 & 0.56 \\
$Q_{t}=K_{k} t^{n}$ & $\mathrm{k}_{\mathrm{KP}}$ & 17.53 & 16.83 & 22.08 & 6.43 \\
\hline$Q_{\infty}$ & $\mathrm{R}^{2}$ & 0.87 & 0.94 & 0.93 & 0.97 \\
\hline
\end{tabular}

Additionally, we used the similarity factor $\left(f_{2}\right)$ to determine whether both methodologies are interchangeable to evaluate drug release. Regarding FDA guidelines, $f_{2}$ values greater than 50 (50-100) show similarity in dissolution profiles. Empirically, this is possible 
if at each point the difference is less than $10 \%$ [75]. We compared and evaluated $f_{2}$ between the profiles from dialysis bag and Franz's cells at $25^{\circ} \mathrm{C}$ and $37^{\circ} \mathrm{C}$, obtaining 56.01 and 50.57, respectively. According to established parameters, both methodologies can be used to determine the drug release from NLC at $25^{\circ} \mathrm{C}$ and $37^{\circ} \mathrm{C}$. It will permit a manual process to be carried out using an automatic method and obtain results in less time. However, both values are within the limit, thus, is difficult to determine if both methodologies are interchangeable reliably. These results indicate that the NLC demonstrated similar drug release in both methods and they are not suitable to show the differences in the drug release process [76].

Once the tests finished, hydrodynamic size, PdI and zeta potential were evaluated to determine if the nanoparticles lost their structure, agglomerated, or changed their surface charge. We observed that the hydrodynamic size increase $\sim 20 \mathrm{~nm}$, this value is attributed to a slight agglomeration (Table 4). As mentioned above and showed in DSC thermograms, the PdI values increase at $37^{\circ} \mathrm{C}$, this could be favored at high temperatures and near the melting point of the solid lipids, allowing the nanoparticles to fuse each other. On the other hand, as mentioned earlier (Section 3.6), the zeta potential was $-18 \mathrm{mV}$, more negative due to the $\mathrm{pH}$ of evaluation ( $\mathrm{pH}$ 7.4). In literature, it has been reported that high salt concentrations cause a reduction of the diffuse layer, then resulting in a decrease of the zeta potential to the neutrality and diminishing the electrostatic repulsion [77]. However, the surface covering of PEG avoids the possibility of perturbing the diffuse layer. Therefore, it shows an increase in PdI due to a weak NLC aggregation after the experiment.

Table 4. Evaluation of NLC-Rho after release studies (72 h). Parameters evaluated were hydrodynamic size $(\mathrm{nm}), \mathrm{PdI}$ and zeta potential $(\mathrm{mV}) . n=3 \pm \mathrm{SD}$.

\begin{tabular}{ccccc}
\hline \multicolumn{2}{c}{ Methodology } & $\begin{array}{c}\text { Hydrodynamic Size } \\
(\mathbf{n m} \pm \mathbf{S D})\end{array}$ & PdI & $\begin{array}{c}\text { Zeta Potential } \\
\text { (mV } \pm \mathbf{S D})\end{array}$ \\
\hline NLC-Rho & $t=0$ & $106.7 \pm 1.6$ & $0.1 \pm 0.01$ & $-9.3 \pm 0.6$ \\
\hline \multirow{2}{*}{ Dialysis bag } & $25^{\circ} \mathrm{C}$ & $118.5 \pm 1.7$ & $0.1 \pm 0.01$ & $-18.4 \pm 1.6$ \\
& $37^{\circ} \mathrm{C}$ & $115.1 \pm 2.8$ & $0.3 \pm 0.01$ & $-19.1 \pm 1.3$ \\
\hline \multirow{2}{*}{ Franz's Cells } & $25^{\circ} \mathrm{C}$ & $117.2 \pm 1.4$ & $0.1 \pm 0.01$ & $-19.0 \pm 1.0$ \\
& $37^{\circ} \mathrm{C}$ & $114.3 \pm 3.1$ & $0.2 \pm 0.01$ & $-16.0 \pm 0.5$ \\
\hline
\end{tabular}

\subsection{Molecular Dynamics Analysis}

In order to better understand the self-assembly behavior of the NLC studied, a molecular modeling of the mixtures was performed. The evaluated systems were named MD-1 corresponding to Miglyol ${ }^{\circledR} 812$, Tween ${ }^{\circledR}$ 80, and Gelucire ${ }^{\circledR}$ 44/14 at $300 \mathrm{~K}$; MD-2, consisting of Tween ${ }^{\circledR} 80$ and Gelucire ${ }^{\circledR} 44 / 14$ at $358 \mathrm{~K}$; MD-3 which is Miglyol ${ }^{\circledR} 812$ absent at a temperature of $358 \mathrm{~K}$, and MD-4 corresponding to Miglyol ${ }^{\circledR} 812$, Tween ${ }^{\circledR} 80$, and Gelucire ${ }^{\circledR}$ $44 / 14$ in the presence of Rho at $358 \mathrm{~K}$ (Table 5). These models were selected to distinguish the effects of electrostatic and hydrophobic interactions on the molecular components self-assembly of the mixed NLC.

Table 5. Molecules used in the simulation of mixed NLC systems.

\begin{tabular}{|c|c|c|c|c|c|}
\hline \multicolumn{2}{|c|}{ Molecules } & \multirow{2}{*}{$\begin{array}{c}\text { MD-1 (300 K) } \\
-\end{array}$} & \multirow{2}{*}{$\begin{array}{c}\text { MD-2 (358 K) } \\
-\end{array}$} & \multirow{2}{*}{$\begin{array}{c}\text { MD-3 (358 K) } \\
-\end{array}$} & \multirow{2}{*}{$\frac{\text { MD-4 (358 K) }}{12}$} \\
\hline Rhodamine & Rhodamine 123 & & & & \\
\hline \multirow{2}{*}{ Miglyol $^{\circledR} 812$} & Capric Triglyceride & 3 & 3 & - & 3 \\
\hline & Caprylic Triglyceride & 3 & 3 & - & 3 \\
\hline Tween ${ }^{\circledR} 80$ & Polysorbate 80 & 8 & 8 & 8 & 8 \\
\hline \multirow{4}{*}{ Gelucire $^{\circledR} 44 / 14$} & Lauric acid PEG & 200 & 200 & 200 & 200 \\
\hline & Mono-glyceride Lauric acid & 17 & 17 & 17 & 17 \\
\hline & Di-glyceride Lauric acid & 17 & 17 & 17 & 17 \\
\hline & Tri-glyceride Lauric acid & 17 & 17 & 17 & 17 \\
\hline
\end{tabular}


The molecular simulations showed that only the MD-2, MD-3, and MD-4 systems at $358 \mathrm{~K}$ were stable in the self-assembly process during the $200 \mathrm{~ns}$ (Figure 7b-d), whereas MD1 mixture at a temperature of $300 \mathrm{~K}$ was not observed during the $200 \mathrm{~ns}$ the self-assembly process to form only one mixed NLC (Figure 7a).

a)

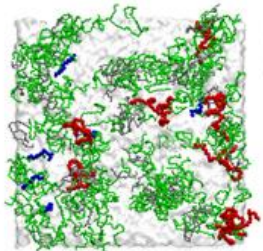

b)

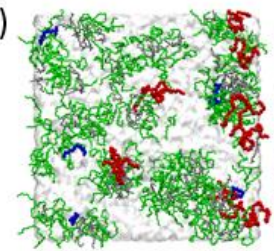

c)

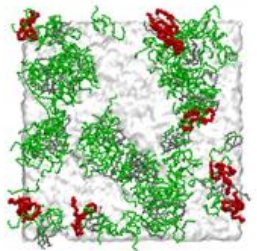

d)

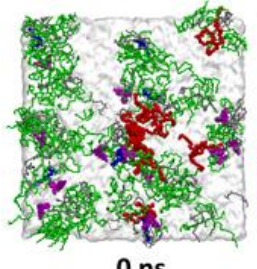

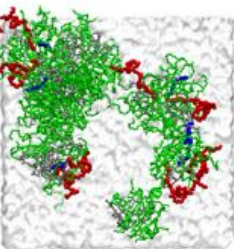
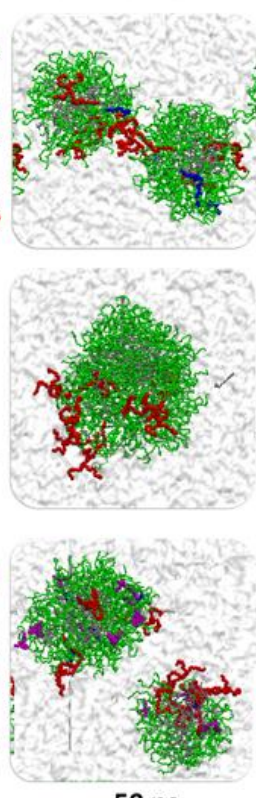
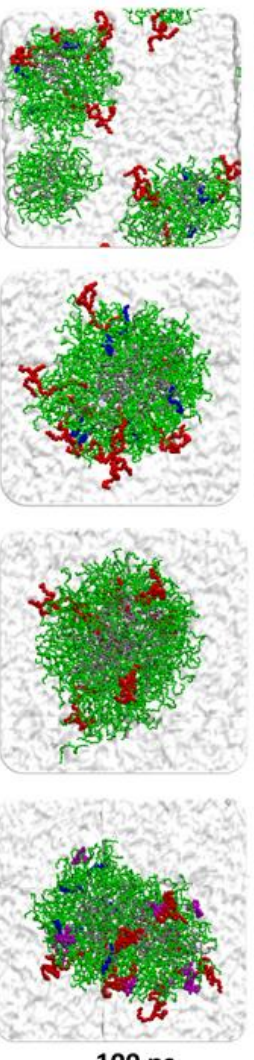

$100 \mathrm{~ns}$
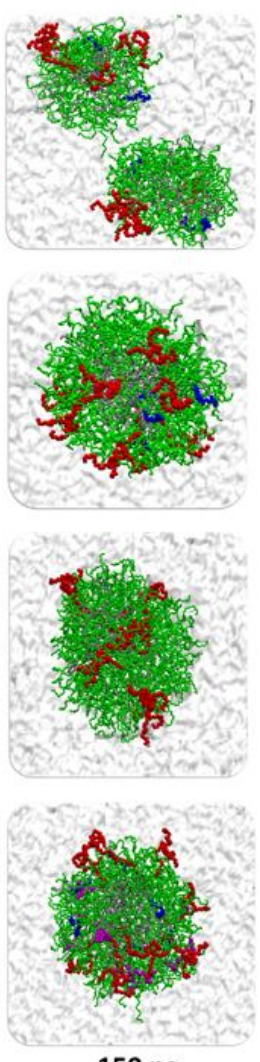
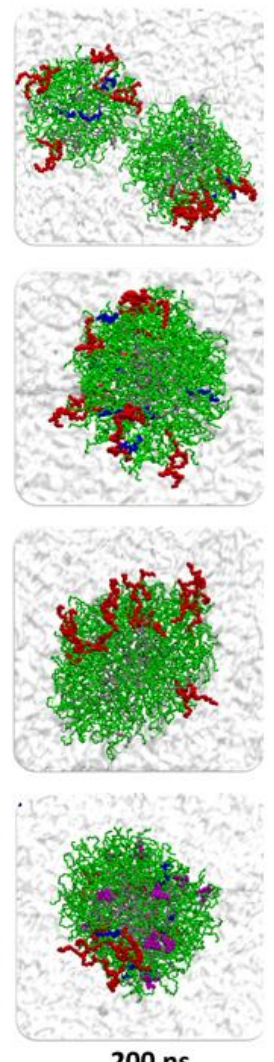

Figure 7. Trajectory snapshots of self-assembly process of (a) MD-1 (Miglyol ${ }^{\circledR} 812$, Tween ${ }^{\circledR} 80$ and Gelucire ${ }^{\circledR} 44 / 14$ at $\left.300 \mathrm{~K}\right)$, (b) MD-2 (Miglyol ${ }^{\circledR} 812$, Tween ${ }^{\circledR} 80$ and Gelucire ${ }^{\circledR} 44 / 14$ at 358 K), (c) MD-3 (Tween ${ }^{\circledR} 80$ and Gelucire ${ }^{\circledR} 44 / 14$ at 358 K) and (d) MD-4 (Rhodamine 123, Miglyol ${ }^{\circledR} 812$, Tween $^{\circledR} 80$ and Gelucire ${ }^{\circledR} 44 / 14$ at $358 \mathrm{~K}$ ) in the aqueous medium at different simulation times. Color representations of Miglyol ${ }^{\circledR} 812$ (blue), Tween ${ }^{\circledR} 80$ (red), Gelucire ${ }^{\circledR} 44 / 14$ (green and gray) and Rhodamine 123 (purple).

These results are in concordance with what we observed experimentally since, at lower temperatures, the nanoparticle formation is less effective (Section 3.1). The mixed NLC formed at $358 \mathrm{~K}$ is not entirely spherical as they have ellipsoidal components. The molecular components of Gelucire ${ }^{\circledR} 44 / 14$, such as lauric acid PEG, are arranged around the hydrophobic center of the lipid nanoparticle formed by Mono-, Di-, and Tri-glyceride lauric acid. This molecular mechanism that produces hydrophobicity is one of the most important factors determining the thermodynamic stability of micelles and biological membranes. Lauric acid PEG on the surface of the NLC allows the torsional movement by which the hydrocarbon chains of lauric acid move in different directions while they associate with other chains of lauric acid PEG. The polar section of Lauric acid PEG can form hydrogen bonds with water molecules in the hydration layer. These hydration water molecules also form a weak hydrogen bond with those in the water. The terminal carbons of Lauric acid interact toward the center of the hydrophobic nucleus with Mono-, Di-, and Tri-glyceride lauric acid, differentiating the amphiphilic surface and the hydrophobic nucleus from the mixed NLC. With the amount of components molecules simulated, the average diameter of the mixed nanoparticles formed during the $200 \mathrm{~ns}$ was $9.2 \mathrm{~nm}$. The molecules of Miglyol ${ }^{\circledR}$ 812 undergo Van der Waals type interactions between the hydrocarbon chains and the 
polar portions of the surface of the mixed NLC constituted by lauric acid PEG, which allows a sufficiently strong anchorage to limit its exchange with the aqueous medium (Figure 7c,d). Consequently, Miglyol ${ }^{\circledR} 812$ is found in small concentrations in water, and practically all its interactions come from hydrophobic areas or near the amphiphilic lauric acid PEG interface. The configuration of Tween ${ }^{\circledR} 80$ in the mixed NLC shows its interaction on the polar PEG surface of lauric acid PEG (Figure 7b-d). This configuration experiences interactions of hydrogen bonds and Van der Waals forces between the ethylene oxides of the chains and the polar portion of the lauric acid PEG.

The aggregation of hydrophobic molecules in the aqueous media is known to be driven by unfavorable contact between water and their hydrophobic domains [78]. It has been shown that as the self-association proceeds, the Solvent Accessible Surface Area (SASA) of the hydrophobic solute is constantly limited in a linear correlation with the unfavorable contacts [79-81]. Thereby, SASA can be used to semi-quantitatively track the self-aggregation of non-soluble agents in the aqueous solvent and see the temperature effect on this self-assembly process. To quantify the self-assembly process, the hydrophobic core of Gelucire ${ }^{\circledR} 44 / 14$ was considered, and the SASA profiles were measured as a function of the simulation time. The SASA profiles of the self-assembly of Mono-, Di-, and Tri-glyceride are shown in Figure 8. Lauric acid at a temperature of $300 \mathrm{~K}$ and $358 \mathrm{~K}$, showing for the mixed NLC system at a temperature of $300 \mathrm{~K}$ greater accessibility to the solvent than the system at a temperature of $358 \mathrm{~K}$, indicating greater self-aggregation. This is confirmed by the progressive decrease in the average number of water particles around each hydrophobic core molecule as SASA becomes more limited. The pattern of SASA variations indicates the staggered formation of larger aggregates from smaller ones, resulting in the system at a temperature of $358 \mathrm{~K}$, a complete mixed NLC system, as also observed in the trajectories.

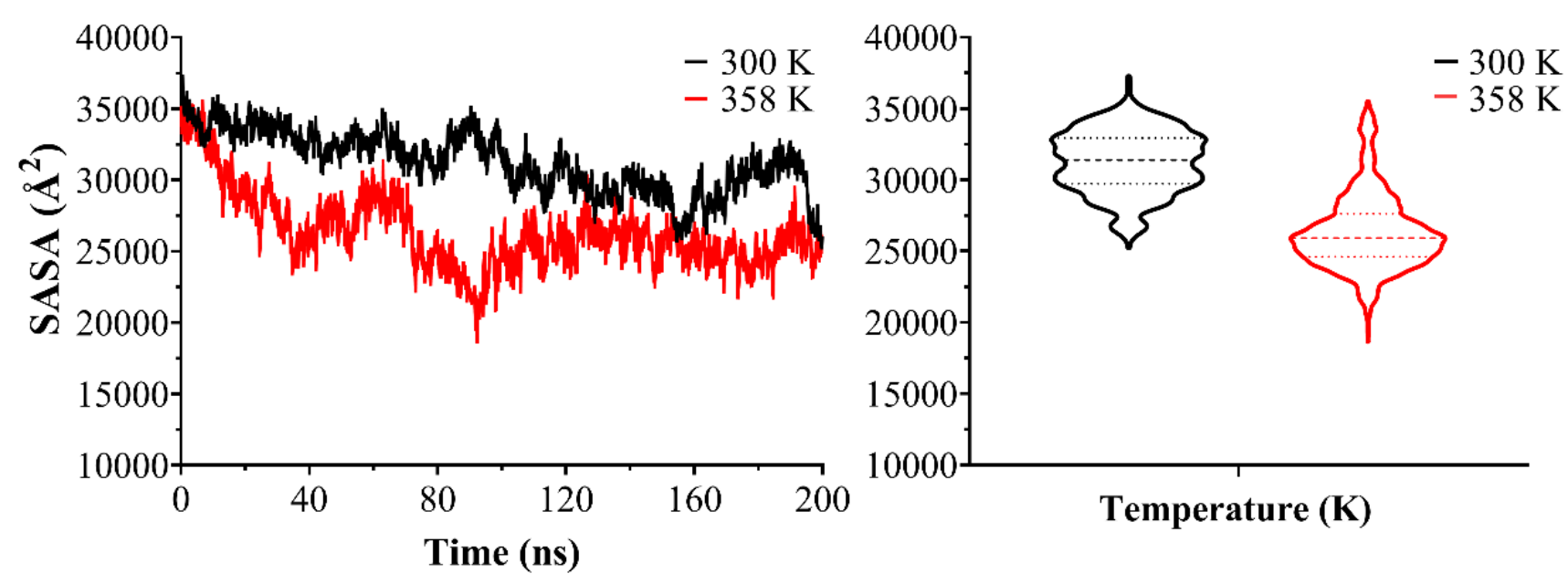

Figure 8. Solvent accessible surface area (SASA) as a function of simulation time for Mono-, Di- and Tri-glyceride Lauric acid at $300 \mathrm{~K}$ (black line) and $358 \mathrm{~K}$ (red line) during the self-association process.

The radial density functions for the tail of lauric acid PEG and oxygen of water molecules from the mixed NLC at a temperature of $300 \mathrm{~K}$ and $358 \mathrm{~K}$ show in Figure 9a greater interaction between lauric acid PEG tails with water molecules when the temperature is $300 \mathrm{~K}$; this is due to the poor self-aggregation process to form a complete mixed NLC. These results are complemented by those obtained in the SASA profiles. The obtained results from the gyration radius (RGyr) give us an insight about how the parameter that gives information on the lipid nanoparticle mass distribution around the center of gravity is an important parameter and can be influenced by Miglyol ${ }^{\circledR} 812$, especially when NLC can adopt several conformations (Figure 9b,c). 
a)

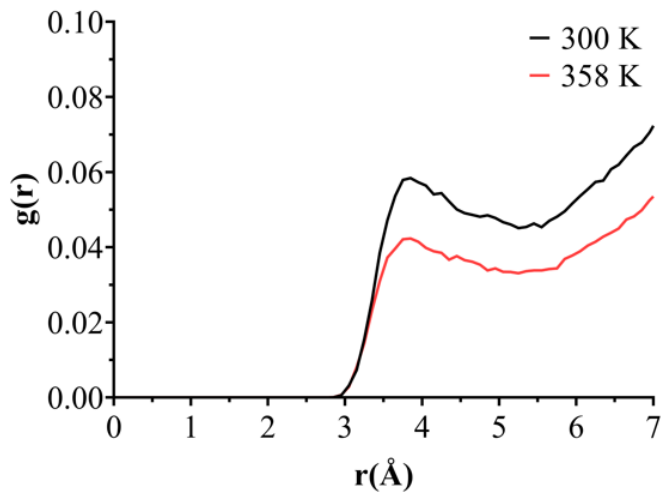

b)

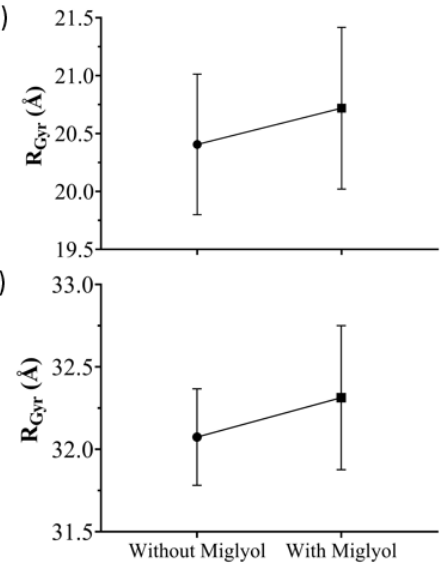

Figure 9. (a) Average radial pair distribution functions (RDF) for oxygen from the water against Lauric acid PEG tail at $300 \mathrm{~K}$ (black line) and $358 \mathrm{~K}$ (red line). The radius of gyration of (b) Mono-, Di- and Tri-glyceride Lauric acid (hydrophobic core) and (c) Lauric acid PEG (amphiphilic surface), in the presence and absence of Miglyol ${ }^{\circledR} 812$ at $358 \mathrm{~K}$.

As mentioned above, a mixture of solid and liquid lipids allows a nanoparticle formation with an imperfect core. According to the obtained results, the Miglyol ${ }^{\circledR} 812$ presence in the nanoparticle structure forms a less compact core, therefore, more imperfect (Figure 10). The mixed NLC system without Miglyol ${ }^{\circledR} 812$ tends to compact and self-aggregate faster than the system with Miglyol ${ }^{\circledR} 812$. This result is consistent with what is shown in Figure 7b,c, in which the mixed NLC system without Miglyol ${ }^{\circledR} 812$ at 45 ns completely self-assembles into a single system. Although the NLC formation with Miglyol $^{\circledR} 812$ is slower, incorporating this material has several advantages. Miglyol ${ }^{\circledR} 812$ improves hydrophobic molecules solubility, increases the incorporation efficiency, and different proportions of solid/liquid lipids allow the molecules release modulation from the matrix. In order to consider the reported values of (RGyr) as significant, a Student's t-test with a $p$-value $<0.05$ was carried out.
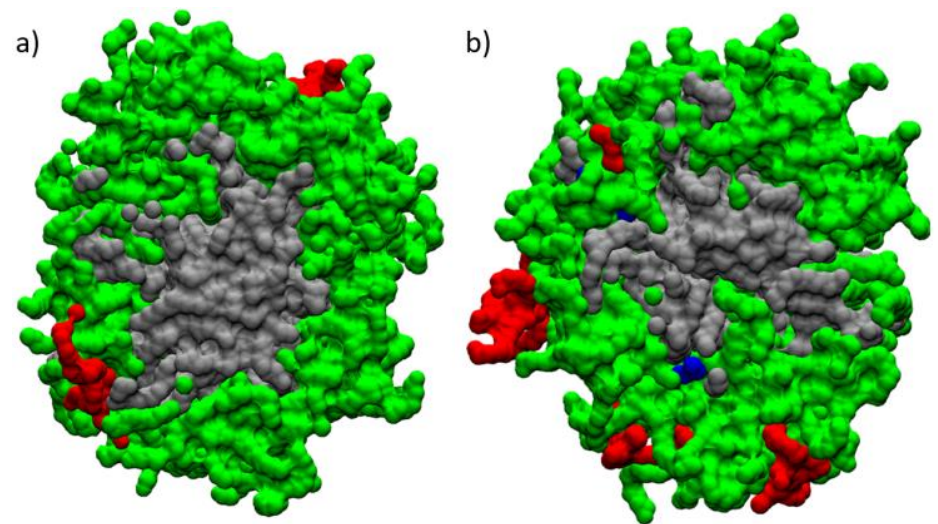

Figure 10. Snapshot of the mixed micelles of Tween ${ }^{\circledR} 80$ (red surf) and Gelucire ${ }^{\circledR} 44 / 14$ (green and gray surf) in the (a) absence and (b) presence of Miglyol ${ }^{\circledR} 812$ (blue surf) at $358 \mathrm{~K}$, along with a cross-sectional view $200 \mathrm{~ns}$ into the simulation trajectory.

For the mixed system MD-4, the molecular simulations showed high stability in the self-assembly process, and in the Rho incorporation during the $200 \mathrm{~ns}$ (Figure 7d) at a temperature of $358 \mathrm{~K}$. Rho 123 molecules interact with the polar phase of lauric acid PEG of Gelucire ${ }^{\circledR} 44 / 14$. For the system with Rho molecules, NCIPLOT isosurface graphs revealed that hydrogen bonds are accompanied by weak and hydrophobic interactions like Van der Waals (Figure 11). The hydrogen bond interaction between Rho and the proposed NLC system is promoted by the lauric acid PEG esters with the two ammonium groups of Rho. 
Weak interactions are made between the Rho rings and the methyl groups of the lauric acid PEG molecule. These interactions give good stability of Rho 123 on the polar surface of the NLC system.

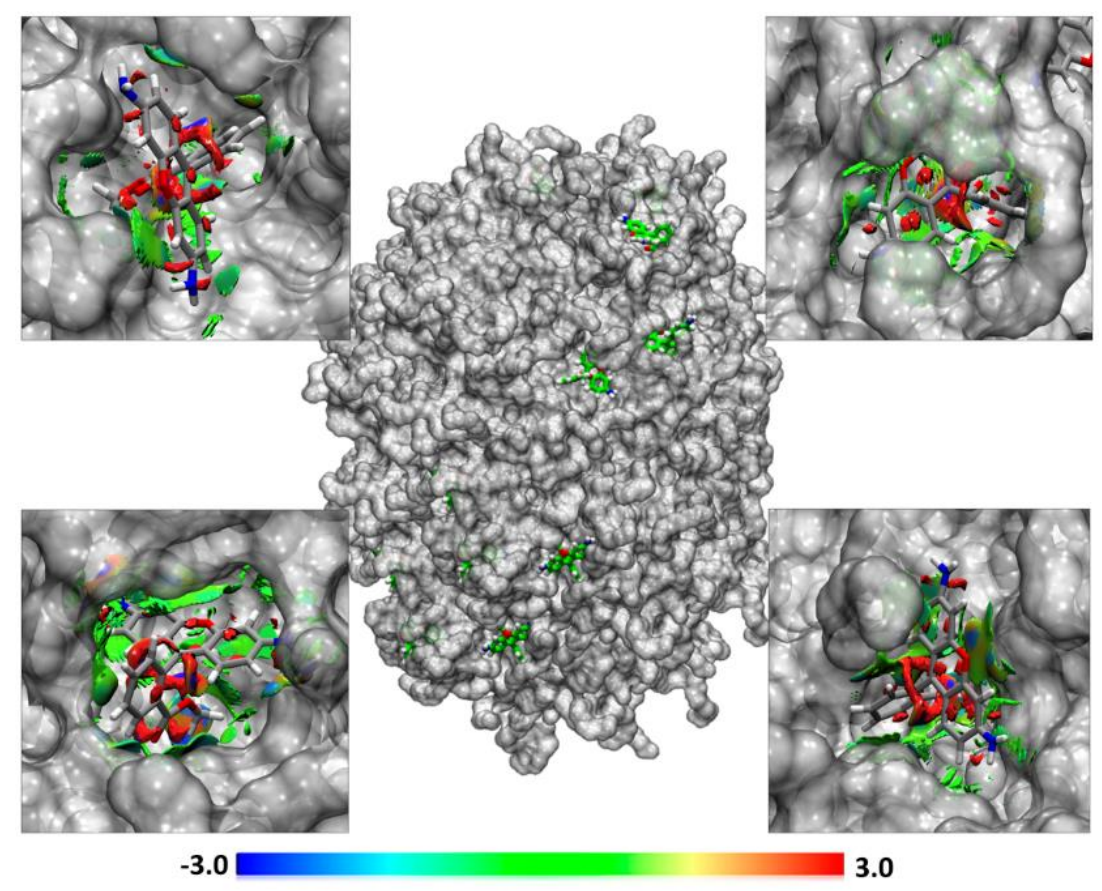

Figure 11. NCIPLOT isosurface gradient $(0.6 \mathrm{au})$ between Rhodamine 123 and mixed NLC of Miglyol ${ }^{\circledR} 812$, Tween ${ }^{\circledR} 80$ and Gelucire ${ }^{\circledR} 44 / 14$. The surfaces were colored on a blue-green-red scale according to the strength and type of interaction. Blue indicates strong attractive interactions, green indicates weak Van der Waals interactions, and red indicates a strong non-bonded overlap.

\section{Conclusions}

In the current research, a nanostructured lipid carrier was successfully manufactured by a low-energy method and characterized by different methodologies. In the formulations studied, a low size distribution was obtained which was maintained in stability studies. Furthermore, the hydrodynamic diameter of the formulation was stable at different $\mathrm{pH}$, therefore, the NLC obtained can be an attractive candidate for oral pharmaceutical formulations. Besides, a poorly-water soluble model molecule was effectively incorporated. The drug release was studied using two different methodologies, these being possibly replaceable under the conditions studied. In all the conditions evaluated, the NLC-Rho release was $\sim 40 \%$ and the Korsmeyer-Peppas fit as the best mathematical model. However, at different temperatures, the release is dominated by different mechanisms due to physical nanoparticle changes. On the other hand, dynamic molecular simulation studies have shown that the NLC formation at high temperatures improves the component compaction and the incorporation of oil in a lipid formulation creates an imperfect core and, therefore, improves the drug loading capacity. Finally, this nanosystem could be an interesting candidate to deliver molecules of low aqueous solubility through the oral route section.

Supplementary Materials: The following are available online at https:/ / www.mdpi.com/article/10 .3390 / pharmaceutics13040531/s1, Table S1: Preliminary formulations leading to the selected NLC $(\% w / w)$ composition. In blue is the selected formulation composition for the current investigation, Figure S1: Hydrodynamic diameter (nm) and zeta potential of all formulation. The formulations not included in the figure were physically unstable.

Author Contributions: J.O.M.: Conceptualization, validation, investigation, resources, writingReview \& editing, visualization, supervision, project administration, funding acquisition. A.C.O.: Conceptualization, methodology, software, validation, formal analysis, investigation, resources, data 
curation, writing-Original draft, writing—review \& editiong, visualization. O.Y.: Methodology, software, formal analysis, data curation, writing-Original draft. E.S.-H.: Writing-Review \& editing. All authors have read and agreed to the published version of the manuscript.

Funding: This research was funded by Regular FONDECYT Project 1181689, ANID/PIA ACT192144, ANID/FONDAP 15130011, ANID/PCI REDI170653, National Doctoral Scholarships 21180654, all granted by Chilean National Agency for Research and Development (ANID).

Conflicts of Interest: The authors declare no conflict of interest.

\section{References}

1. Hu, Y.; Niemeyer, C.M. From DNA Nanotechnology to Material Systems Engineering. Adv. Mater. 2019, 31, 1806294. [CrossRef]

2. Cheon, J.; Chan, W.; Zuhorn, I. The Future of Nanotechnology: Cross-Disciplined Progress to Improve Health and Medicine. Acc. Chem. Res. 2019, 52, 2405. [CrossRef]

3. Zeng, L.; Xiao, L.; Zhang, J.; Fu, H. The Role of Nanotechnology in Subgrade and Pavement Engineering: A Review. J. Nanosci. Nanotechnol. 2020, 20, 4607-4618. [CrossRef]

4. Bayón-Cordero, L.; Alkorta, I.; Arana, L. Application of Solid Lipid Nanoparticles to Improve the Efficiency of Anticancer Drugs. Nanomaterials 2019, 9, 474. [CrossRef] [PubMed]

5. Subramaniam, B.; Siddik, Z.H.; Nagoor, N.H. Optimization of Nanostructured Lipid Carriers: Understanding the Types, Designs, and Parameters in the Process of Formulations. J. Nanopart. Res. 2020, 22, 141. [CrossRef]

6. Jaiswal, P.; Gidwani, B.; Vyas, A. Nanostructured Lipid Carriers and Their Current Application in Targeted Drug Delivery. Artif. Cells Nanomed. Biotechnol. 2016, 44, 27-40. [CrossRef] [PubMed]

7. Khosa, A.; Reddi, S.; Saha, R.N. Nanostructured Lipid Carriers for Site-Specific Drug Delivery. Biomed. Pharmacother. 2018, 103, 598-613. [CrossRef] [PubMed]

8. Chen, J.; Hu, L. Nanoscale Delivery System for Nutraceuticals: Preparation, Application, Characterization, Safety, and Future Trends. Food Eng. Rev. 2020, 12, 14-31. [CrossRef]

9. Nothnagel, L.; Wacker, M.G. How to Measure Release from Nanosized Carriers? Eur. J. Pharm. Sci. 2018, 120, 199-211. [CrossRef]

10. Sheshala, R.; Anuar, N.K.; Abu Samah, N.H.; Wong, T.W. In Vitro Drug Dissolution/Permeation Testing of Nanocarriers for Skin Application: A Comprehensive Review. AAPS PharmSciTech 2019, 20, 164. [CrossRef]

11. Yu, M.; Yuan, W.; Li, D.; Schwendeman, A.; Schwendeman, S.P. Predicting Drug Release Kinetics from Nanocarriers inside Dialysis Bags. J. Control. Release 2019, 315, 23-30. [CrossRef] [PubMed]

12. Karplus, M.; McCammon, J.A. Molecular Dynamics Simulations of Biomolecules. Nat. Struct. Biol. 2002, 9, 646-652. [CrossRef]

13. Zhang, W.; Li, X.; Ye, T.; Chen, F.; Sun, X.; Kong, J.; Yang, X.; Pan, W.; Li, S. Design, Characterization, and in Vitro Cellular Inhibition and Uptake of Optimized Genistein-Loaded NLC for the Prevention of Posterior Capsular Opacification Using Response Surface Methodology. Int. J. Pharm. 2013, 454, 354-366. [CrossRef] [PubMed]

14. Ditchfield, R. Self-Consistent Molecular-Orbital Methods. IX. An Extended Gaussian-Type Basis for Molecular-Orbital Studies of Organic Molecules. J. Chem. Phys. 1971, 54, 724. [CrossRef]

15. Becke, A.D. Density-functional Thermochemistry. III. The Role of Exact Exchange. J. Chem. Phys. 1993, 98, 5648-5652. [CrossRef]

16. Dodda, L.S.; Vilseck, J.Z.; Tirado-Rives, J.; Jorgensen, W.L. 1.14*CM1A-LBCC: Localized Bond-Charge Corrected CM1A Charges for Condensed-Phase Simulations. J. Phys. Chem. B 2017, 121, 3864-3870. [CrossRef]

17. Dodda, L.S.; Cabeza de Vaca, I.; Tirado-Rives, J.; Jorgensen, W.L. LigParGen Web Server: An Automatic OPLS-AA Parameter Generator for Organic Ligands. Nucleic Acids Res. 2017, 45, W331-W336. [CrossRef] [PubMed]

18. Jorgensen, W.L.; Tirado-Rives, J. Potential Energy Functions for Atomic-Level Simulations of Water and Organic and Biomolecular Systems. Proc. Natl. Acad. Sci. USA 2005, 102, 6665-6670. [CrossRef] [PubMed]

19. Eastman, P.; Swails, J.; Chodera, J.D.; McGibbon, R.T.; Zhao, Y.; Beauchamp, K.A.; Wang, L.P.; Simmonett, A.C.; Harrigan, M.P.; Stern, C.D.; et al. OpenMM 7: Rapid Development of High Performance Algorithms for Molecular Dynamics. PLoS Comput. Biol. 2017, 13, 1-17. [CrossRef]

20. Eastman, P.; Pande, V.S. Constant Constraint Matrix Approximation: A Robust, Parallelizable Constraint Method for Molecular Simulations. J. Chem. Theory Comput. 2010, 6, 434-437. [CrossRef]

21. Wang, L.-P.; Martinez, T.J.; Pande, V.S. Building Force Fields: An Automatic, Systematic, and Reproducible Approach. J. Phys. Chem. Lett. 2014, 5, 1885-1891. [CrossRef] [PubMed]

22. Martínez, L.; Andrade, R.; Birgin, E.G.; Martínez, J.M. Packmol: A Package for Building Initial Configurations for Molecular Dynamics Simulations. J. Comput. Chem. 2009, 30, 2157-2164. [CrossRef] [PubMed]

23. Humphrey, W.; Dalke, A.; Schulten, K. VMD: Visual Molecular Dynamics. J. Mol. Graph. 1996, 14, 33-38. [CrossRef]

24. Contreras-García, J.; Johnson, E.R.; Keinan, S.; Chaudret, R.; Piquemal, J.-P.; Beratan, D.N.; Yang, W. NCIPLOT: A Program for Plotting Noncovalent Interaction Regions. J. Chem. Theory Comput. 2011, 7, 625-632. [CrossRef]

25. Johnson, E.R.; Keinan, S.; Mori-Sánchez, P.; Contreras-García, J.; Cohen, A.J.; Yang, W. Revealing Noncovalent Interactions. J. Am. Chem. Soc. 2010, 132, 6498-6506. [CrossRef]

26. Tapeinos, C.; Battaglini, M.; Ciofani, G. Advances in the Design of Solid Lipid Nanoparticles and Nanostructured Lipid Carriers for Targeting Brain Diseases. J. Control. Release 2017, 264, 306-332. [CrossRef] 
27. Joos, A.; Weiss, J.; McClements, D.J. Fabrication of Lipophilic Nanoparticles by Spontaneous Emulsification: Stabilization by Cosurfactants. Food Biophys 2015, 10, 83-93. [CrossRef]

28. Gordillo-Galeano, A.; Mora-Huertas, C.E. Solid Lipid Nanoparticles and Nanostructured Lipid Carriers: A Review Emphasizing on Particle Structure and Drug Release. Eur. J. Pharm. Biopharm. 2018, 133, 285-308. [CrossRef] [PubMed]

29. Chen, P.; Zhang, H.; Cheng, S.; Zhai, G.; Shen, C. Development of Curcumin Loaded Nanostructured Lipid Carrier Based Thermosensitive in Situ Gel for Dermal Delivery. Colloids Surf. Physicochem. Eng. Asp. 2016, 506, 356-362. [CrossRef]

30. Carbone, C.; Campisi, A.; Musumeci, T.; Raciti, G.; Bonfanti, R.; Puglisi, G. FA-Loaded Lipid Drug Delivery Systems: Preparation, Characterization and Biological Studies. Eur. J. Pharm. Sci. 2014, 52, 12-20. [CrossRef]

31. Sun, M.; Zhu, Z.; Wang, H.; Han, C.; Liu, D.; Tian, L.; Yang, X.; Pan, W. Surface Density of Polyarginine Influence the Size, Zeta Potential, Cellular Uptake and Tissue Distribution of the Nanostructured Lipid Carrier. Drug Deliv. 2017, 24, 519-526. [CrossRef]

32. Babazadeh, A.; Ghanbarzadeh, B.; Hamishehkar, H. Formulation of Food Grade Nanostructured Lipid Carrier (NLC) for Potential Applications in Medicinal-Functional Foods. J. Drug Deliv. Sci. Technol. 2017, 39, 50-58. [CrossRef]

33. Alvarez-Trabado, J.; Diebold, Y.; Sanchez, A. Designing Lipid Nanoparticles for Topical Ocular Drug Delivery. Int. J. Pharm. 2017, 532, 204-217. [CrossRef]

34. Marengo, E.; Cavalli, R.; Caputo, O.; Rodriguez, L.; Gasco, M.R. Scale-up of the Preparation Process of Solid Lipid Nanospheres. Part I. Int. J. Pharm. 2000, 205, 3-13. [CrossRef]

35. Gao, S.; McClements, D.J. Formation and Stability of Solid Lipid Nanoparticles Fabricated Using Phase Inversion Temperature Method. Colloids Surf. Physicochem. Eng. Asp. 2016, 499, 79-87. [CrossRef]

36. Mehnert, W.; Mäder, K. Solid Lipid Nanoparticles: Production, Characterization and Applications. Adv. Drug Deliv. Rev. 2001, 47, 165-196. [CrossRef]

37. Fernandez, S.; Rodier, J.-D.; Ritter, N.; Mahler, B.; Demarne, F.; Carrière, F.; Jannin, V. Lipolysis of the Semi-Solid Self-Emulsifying Excipient Gelucire $^{\circledR} 44 / 14$ by Digestive Lipases. Biochim. Biophys. Acta BBA Mol. Cell Biol. Lipids 2008, 1781, 367-375. [CrossRef]

38. Panigrahi, K.C.; Patra, C.N.; Jena, G.K.; Ghose, D.; Jena, J.; Panda, S.K.; Sahu, M. Gelucire: A Versatile Polymer for Modified Release Drug Delivery System. Future J. Pharm. Sci. 2018, 4, 102-108. [CrossRef]

39. García-Pinel, B.; Porras-Alcalá, C.; Ortega-Rodríguez, A.; Sarabia, F.; Prados, J.; Melguizo, C.; López-Romero, J.M. Lipid-Based Nanoparticles: Application and Recent Advances in Cancer Treatment. Nanomaterials 2019, 9, 638. [CrossRef] [PubMed]

40. Lukovac, S.; Gooijert, K.E.G.; Gregory, P.C.; Shlieout, G.; Stellaard, F.; Rings, E.H.H.M.; Verkade, H.J. Gelucire ${ }^{\circledR} 44 / 14$ Improves Fat Absorption in Rats with Impaired Lipolysis. Biochim. Biophys. Acta BBA Mol. Cell Biol. Lipids 2010, 1801, 665-673. [CrossRef] [PubMed]

41. Sukhanova, A.; Bozrova, S.; Sokolov, P.; Berestovoy, M.; Karaulov, A.; Nabiev, I. Dependence of Nanoparticle Toxicity on Their Physical and Chemical Properties. Nanoscale Res. Lett. 2018, 13, 44. [CrossRef]

42. Pimentel-Moral, S.; Teixeira, M.C.; Fernandes, A.R.; Borrás-Linares, I.; Arráez-Román, D.; Martínez-Férez, A.; Segura-Carretero, A.; Souto, E.B. Polyphenols-Enriched Hibiscus Sabdariffa Extract-Loaded Nanostructured Lipid Carriers (NLC): Optimization by Multi-Response Surface Methodology. J. Drug Deliv. Sci. Technol. 2019, 49, 660-667. [CrossRef]

43. Baig, M.S.; Owida, H.; Njoroge, W.; Siddiqui, A.-R.; Yang, Y. Development and Evaluation of Cationic Nanostructured Lipid Carriers for Ophthalmic Drug Delivery of Besifloxacin. J. Drug Deliv. Sci. Technol. 2020, 55, 101496. [CrossRef]

44. Levit, S.L.; Stwodah, R.M.; Tang, C. Rapid, Room Temperature Nanoparticle Drying and Low-Energy Reconstitution via Electrospinning. J. Pharm. Sci. 2018, 107, 807-813. [CrossRef] [PubMed]

45. Tsai, M.-J.; Wu, P.-C.; Huang, Y.-B.; Chang, J.-S.; Lin, C.-L.; Tsai, Y.-H.; Fang, J.-Y. Baicalein Loaded in Tocol Nanostructured Lipid Carriers (Tocol NLCs) for Enhanced Stability and Brain Targeting. Int. J. Pharm. 2012, 423, 461-470. [CrossRef] [PubMed]

46. Tamjidi, F.; Shahedi, M.; Varshosaz, J.; Nasirpour, A. Design and Characterization of Astaxanthin-Loaded Nanostructured Lipid Carriers. Innov. Food Sci. Emerg. Technol. 2014, 26, 366-374. [CrossRef]

47. Adabi, M.; Naghibzadeh, M.; Adabi, M.; Zarrinfard, M.A.; Esnaashari, S.S.; Seifalian, A.M.; Faridi-Majidi, R.; Aiyelabegan, H.T.; Ghanbari, H. Biocompatibility and Nanostructured Materials: Applications in Nanomedicine. Artif. Cells Nanomed. Biotechnol. 2017, 45, 833-842. [CrossRef]

48. Yue, Z.-G.; Wei, W.; Lv, P.-P.; Yue, H.; Wang, L.-Y.; Su, Z.-G.; Ma, G.-H. Surface Charge Affects Cellular Uptake and Intracellular Trafficking of Chitosan-Based Nanoparticles. Biomacromolecules 2011, 12, 2440-2446. [CrossRef]

49. He, C.; Hu, Y.; Yin, L.; Tang, C.; Yin, C. Effects of Particle Size and Surface Charge on Cellular Uptake and Biodistribution of Polymeric Nanoparticles. Biomaterials 2010, 31, 3657-3666. [CrossRef]

50. Kedmi, R.; Ben-Arie, N.; Peer, D. The Systemic Toxicity of Positively Charged Lipid Nanoparticles and the Role of Toll-like Receptor 4 in Immune Activation. Biomaterials 2010, 31, 6867-6875. [CrossRef]

51. Filipe, V.; Hawe, A.; Jiskoot, W. Critical Evaluation of Nanoparticle Tracking Analysis (NTA) by NanoSight for the Measurement of Nanoparticles and Protein Aggregates. Pharm. Res. 2010, 27, 796-810. [CrossRef]

52. Nnamani, P.O.; Hansen, S.; Windbergs, M.; Lehr, C.-M. Development of Artemether-Loaded Nanostructured Lipid Carrier (NLC) Formulation for Topical Application. Int. J. Pharm. 2014, 477, 208-217. [CrossRef]

53. Varma, L.T.; Singh, N.; Gorain, B.; Choudhury, H.; Tambuwala, M.M.; Kesharwani, P.; Shukla, R. Recent Advances in SelfAssembled Nanoparticles for Drug Delivery. Curr. Drug Deliv. 2020, 17, 279-291. [CrossRef] [PubMed]

54. Bhattacharjee, S. DLS and Zeta Potential-What They Are and What They Are Not? J. Control. Release 2016, $235,337-351$. [CrossRef] [PubMed] 
55. Damian, F.; Blaton, N.; Naesens, L.; Balzarini, J.; Kinget, R.; Augustijns, P.; Van den Mooter, G. Physicochemical Characterization of Solid Dispersions of the Antiviral Agent UC-781 with Polyethylene Glycol 6000 and Gelucire 44/14. Eur. J. Pharm. Sci. 2000, 10, 311-322. [CrossRef]

56. Caon, T.; Konig, R.A.; da Cruz, A.C.C.; Cardoso, S.G.; Campos, C.E.M.; Cuffini, S.L.; Koester, L.S.; Simões, C.M.O. Development and Physicochemical Characterization of Saquinavir Mesylate Solid Dispersions Using Gelucire 44/14 or PEG 4000 as Carrier. Arch. Pharm. Res. 2013, 36, 1113-1125. [CrossRef] [PubMed]

57. Čerpnjak, K.; Zvonar, A.; Vrečer, F.; Gašperlin, M. Development of a Solid Self-Microemulsifying Drug Delivery System (SMEDDS) for Solubility Enhancement of Naproxen. Drug Dev. Ind. Pharm. 2015, 41, 1548-1557. [CrossRef] [PubMed]

58. Lee, M.K.; Kim, M.Y.; Kim, S.; Lee, J. Cryoprotectants for Freeze Drying of Drug Nano-Suspensions: Effect of Freezing Rate. J. Pharm. Sci. 2009, 98, 4808-4817. [CrossRef]

59. Varshosaz, J.; Eskandari, S.; Tabbakhian, M. Freeze-Drying of Nanostructure Lipid Carriers by Different Carbohydrate Polymers Used as Cryoprotectants. Carbohydr. Polym. 2012, 88, 1157-1163. [CrossRef]

60. Abdelwahed, W.; Degobert, G.; Fessi, H. Investigation of Nanocapsules Stabilization by Amorphous Excipients during FreezeDrying and Storage. Eur. J. Pharm. Biopharm. 2006, 63, 87-94. [CrossRef] [PubMed]

61. Ortiz, A.C.; Casas, I.; Mella, P.; Naranjo, O.; Pizarro, N.; Vega, A.; Cerda-Opazo, P.; García, L.; Morales, J.O.; Cepeda-Plaza, M. Aptamer-Functionalized Lipid-Core Micelles Loaded with Rhenium Tricarbonyl Complex. Polyhedron 2021, $195,114963$. [CrossRef]

62. Salvi, V.R.; Pawar, P. Nanostructured Lipid Carriers (NLC) System: A Novel Drug Targeting Carrier. J. Drug Deliv. Sci. Technol. 2019, 51, 255-267. [CrossRef]

63. Safwat, S.; Ishak, R.A.H.; Hathout, R.M.; Mortada, N.D. Nanostructured Lipid Carriers Loaded with Simvastatin: Effect of PEG/Glycerides on Characterization, Stability, Cellular Uptake Efficiency and in Vitro Cytotoxicity. Drug Dev. Ind. Pharm. 2017, 43, 1112-1125. [CrossRef]

64. Bashiri, S.; Ghanbarzadeh, B.; Ayaseh, A.; Dehghannya, J.; Ehsani, A. Preparation and Characterization of Chitosan-Coated Nanostructured Lipid Carriers (CH-NLC) Containing Cinnamon Essential Oil for Enriching Milk and Anti-Oxidant Activity. LWT 2020, 119, 108836. [CrossRef]

65. Nakach, M.; Authelin, J.-R.; Tadros, T.; Galet, L.; Chamayou, A. Engineering of Nano-Crystalline Drug Suspensions: Employing a Physico-Chemistry Based Stabilizer Selection Methodology or Approach. Int. J. Pharm. 2014, 476, 277-288. [CrossRef]

66. Choi, K.-O.; Aditya, N.P.; Ko, S. Effect of Aqueous PH and Electrolyte Concentration on Structure, Stability and Flow Behavior of Non-Ionic Surfactant Based Solid Lipid Nanoparticles. Food Chem. 2014, 147, 239-244. [CrossRef]

67. Park, S.J.; Garcia, C.V.; Shin, G.H.; Kim, J.T. Development of Nanostructured Lipid Carriers for the Encapsulation and Controlled Release of Vitamin D3. Food Chem. 2017, 225, 213-219. [CrossRef]

68. Ozturk, B.; Argin, S.; Ozilgen, M.; McClements, D.J. Nanoemulsion Delivery Systems for Oil-Soluble Vitamins: Influence of Carrier Oil Type on Lipid Digestion and Vitamin D3 Bioaccessibility. Food Chem. 2015, 187, 499-506. [CrossRef] [PubMed]

69. Soleimanian, Y.; Goli, S.A.H.; Varshosaz, J.; Di Cesare Mannelli, L.; Ghelardini, C.; Cirri, M.; Maestrelli, F. $\beta$-Sitosterol Loaded Nanostructured Lipid Carrier: Physical and Oxidative Stability, In Vitro Simulated Digestion and Hypocholesterolemic Activity. Pharmaceutics 2020, 12, 386. [CrossRef] [PubMed]

70. Tamjidi, F.; Shahedi, M.; Varshosaz, J.; Nasirpour, A. Nanostructured Lipid Carriers (NLC): A Potential Delivery System for Bioactive Food Molecules. Innov. Food Sci. Emerg. Technol. 2013, 19, 29-43. [CrossRef]

71. Garg, N.K.; Tyagi, R.K.; Singh, B.; Sharma, G.; Nirbhavane, P.; Kushwah, V.; Jain, S.; Katare, O.P. Nanostructured Lipid Carrier Mediates Effective Delivery of Methotrexate to Induce Apoptosis of Rheumatoid Arthritis via NF-KB and FOXO1. Int. J. Pharm. 2016, 499, 301-320. [CrossRef]

72. Mathematical models of drug release. In Strategies to Modify the Drug Release from Pharmaceutical Systems; Bruschi, M.L. (Ed.) Woodhead Publishing: Sawston, UK, 2015; pp. 63-86, ISBN 978-0-08-100092-2.

73. Alam, M.; Nikita, S.A.; Moon, G.; Aqil, M.; Sultana, Y. Chemical Engineering of a Lipid Nano-Scaffold for the Solubility Enhancement of an Antihyperlipidaemic Drug, Simvastatin; Preparation, Optimization, Physicochemical Characterization and Pharmacodynamic Study. Artif. Cells Nanomed. Biotechnol. 2018, 46, 1908-1919. [CrossRef]

74. Suk, V.R.E.; Latif, F.M.; Teo, Y.Y.; Misran, M. Development of Nanostructured Lipid Carrier (NLC) Assisted with Polysorbate Nonionic Surfactants as a Carrier for 1-Ascorbic Acid and Gold Tri.E 30. J. Food Sci. Technol. 2020. [CrossRef]

75. Jelvehgari, M.; Zakeri-Milani, P.; Siahi-Shadbad, M.R.; Loveymi, B.D.; Nokhodchi, A.; Azari, Z.; Valizadeh, H. Development of PH-Sensitive Insulin Nanoparticles Using Eudragit L100-55 and Chitosan with Different Molecular Weights. AAPS PharmSciTech 2010, 11, 1237-1242. [CrossRef]

76. Balzus, B.; Colombo, M.; Sahle, F.F.; Zoubari, G.; Staufenbiel, S.; Bodmeier, R. Comparison of Different in Vitro Release Methods Used to Investigate Nanocarriers Intended for Dermal Application. Int. J. Pharm. 2016, 513, 247-254. [CrossRef] [PubMed]

77. Rowe, E.L. Effect of Emulsifier Concentration and Type on the Particle Size Distribution of Emulsions. J. Pharm. Sci. 1965, 54, 260-264. [CrossRef]

78. Schreier, S.; Malheiros, S.V.P.; de Paula, E. Surface Active Drugs: Self-Association and Interaction with Membranes and Surfactants. Physicochemical and Biological Aspects. Biochim. Biophys. Acta BBA Biomembr. 2000, 1508, 210-234. [CrossRef]

79. Chandler, D. Interfaces and the Driving Force of Hydrophobic Assembly. Nature 2005, 437, 640-647. [CrossRef] 
80. Stephenson, B.C.; Goldsipe, A.; Blankschtein, D. Molecular Dynamics Simulation and Thermodynamic Modeling of the SelfAssembly of the Triterpenoids Asiatic Acid and Madecassic Acid in Aqueous Solution. J. Phys. Chem. B 2008, 112, $2357-2371$. [CrossRef]

81. Wang, X.-Y.; Zhang, L.; Wei, X.-H.; Wang, Q. Molecular Dynamics of Paclitaxel Encapsulated by Salicylic Acid-Grafted Chitosan Oligosaccharide Aggregates. Biomaterials 2013, 34, 1843-1851. [CrossRef] [PubMed] 